\title{
An exergy-based multi-objective optimisation model for energy retrofit strategies in non-domestic buildings
}

\author{
Iván García Kerdan ${ }^{\mathrm{a},{ }^{*},{ }}$ Rokia Raslan ${ }^{\mathrm{b}}$, Paul Ruyssevelt $^{\mathrm{a}}$ \\ a Energy Institute, University College London, 14 Upper Woburn PI, London, WC1H 0NN, U.K. \\ $\mathrm{b}$ Institute of Environmental Design and Engineering, University College London, 14 Upper Woburn PI, \\ London, WC1H ONN, U.K.
}

\begin{abstract}
While the building sector has a significant thermodynamic improvement potential, exergy analysis has been shown to provide new insight for the optimisation of building energy systems. This paper presents an exergy-based multi-objective optimisation tool that aims to assess the impact of a diverse range of retrofit measures with a focus on non-domestic buildings. EnergyPlus was used as a dynamic calculation engine for first law analysis, while a Python add-on was developed to link dynamic exergy analysis and a Genetic Algorithm optimisation process with the aforementioned software. Two UK archetype case studies (an office and a primary school) were used to test the feasibility of the proposed framework. Different measures combinations based on retrofitting the envelope insulation levels and the application of different HVAC configurations were assessed. The objective functions in this study are annual energy use, occupants' thermal comfort, and total building exergy destructions. A large range of optimal solutions was achieved highlighting the framework capabilities. The model achieved improvements of $53 \%$ in annual energy use, $51 \%$ of exergy destructions and $66 \%$ of thermal comfort for the school building, and 50\%, 33\%, and $80 \%$ for the office building. This approach can be extended by using exergoeconomic optimisation.
\end{abstract}

\footnotetext{
Keywords:

Building Simulation; Exergy; Optimisation; Genetic Algorithms; Building retrofits; Nondomestic buildings.

${ }^{*}$ Corresponding author at: Energy Institute, University College London, United Kingdom. Tel: +44 (0) 7867798730

E-mail address: i.kerdan.12@ucl.ac.uk (I. Garcia Kerdan)
} 


\section{Introduction}

To address the UK's national dependency on high quality energy sources such as, natural gas and coal, recent energy policies and regulatory shifts have aimed to improve cross-sectoral efficiency. At present, the UK non-domestic building sector is responsible for $17 \%$ of the country's total energy use and is highly dependent on fossil fuels (60\% gas, $10 \%$ oil, and $25 \%$ non-renewable electricity) [1]. Particularly, in the English and Welsh non-domestic building sector, the final energy utilisation in 2013 was estimated to be 840.9 PJ (equivalent to 20.085 Mtoe annually) with a primary energy input of 1576.9 PJ [2]. From an end-use perspective, about $50 \%$ of all energy demand in the sector was due to space heating, followed by lighting (17\%), DHW (10\%) and catering $(10 \%)$. As the majority of nondomestic buildings were built before energy regulations were implemented, this resulted in poor fabric characteristics, inefficient HVAC equipment and controls, and poor occupant energy awareness and comfort levels [3]. Also, the expansion of HVAC systems in new and existing buildings represent higher energy usage rates every year, mainly driven by the constant increasing of cooling demands. In addition, the building replacement rate is typically low (<2\%) [4], and although is expected that by 2050 the footprint will increase by a third, $80 \%$ of existing buildings will still be in use. In this sense, energy retrofit measures (ERMs) represent a significant opportunity to reduce existing buildings energy use and carbon emissions.

Currently in the UK, there are a wide range of building energy codes and programmes that encourage the implementation of ERMs on existing buildings by setting minimum values for energy efficiency. For example, Part L2B [5] sets minimal envelope insulation levels when retrofits actions are implemented in existing non-domestic buildings. Moreover, a number of financial mechanisms have been introduced in an aim to drive down demand and improve efficiency (e.g. Climate Change Levy, CRC Energy Efficiency Scheme, ESOS). In addition, policies to support the implementation of low carbon HVAC systems have been developed (Energy Labelling Directive, Renewable Heat Incentive), where technologies such as biomass boilers, heat pumps, and solar thermal equipment are widely supported. Other example at a European level is the recast of the Energy Performance of Buildings Regulations [6]. The directive took effect in 2013 and among the articles; it sets minimum energy performance requirements on all renovated buildings (Article 7 ) as well as minimum energy performance on energy 
systems retrofits (Article 8). The directive seeks that ERMs projects should aim to achieve a trade-off between energy saving and cost-effectiveness.

\section{Background}

\subsection{Simulation-based tools and optimisation of ERMs}

With the current range of available technologies and measures, the identification of the most appropriate of these is a critical aspect of the early design phase. As with any energy system, buildings are physically complex systems where interactions between the building, the occupants, the equipment, and the environment are poorly understood. In order to improve the selection of appropriate measures, practitioners require robust tools for effective design, where building simulation play a major role in the design of energy efficient buildings [7]. The use of simulation tools for ERMs represents a quick and cost-effective method to estimate pre and post retrofit energy use of a building. Although building simulation tools lack direct orientation to retrofit analysis, the outputs can be used in life cycle cost analysis tools to calculate energy and cost savings in the future. Too overcome this, several retrofit oriented tools have been developed in the last decade. Hong [8] provided a review of 18 retrofit toolkits categorized in three kinds of methods: a) empirical data driven, b) normative calculations, and c) physics-based modelling. The latest provide the highest fidelity but with the drawback of being more complex because of the need of more input data and longer simulation times. These tools commonly use as the main energy calculation engine open source tools such as DOE 2.2 [9] and EnergyPlus [10]. Among the most recent developments are ROBESim [11], CBES [12] and SLABE [13]. On the other hand, Rysanek and Choudhary [14] developed an exhaustive retrofit simulation tool using TRNSYS [15] and MatLab [16]; the tool is capable to simulate a large set of building retrofit strategies under economic uncertainty.

In practice, the most common approach to assess a wide range of retrofit strategies is the "scenario by scenario" approach, where the practitioner models several solutions based on experience. The main limitation associated with this approach is that the number of analysed scenarios is typically very low, which often leads to solutions that can be far from optimal. In recent years, parametric or full factorial tools have been developed. In this method, a large number of simulations are carried out in order to assess all the possible combinations, usually having a search space of thousands of solutions with the 
certainty of reaching the theoretical optimal scenario. This method has the strength that can provide a large amount of data that, for example, can be used to train artificial neural networks (ANN) [17]. However, in practice the method presents the limitation that is computationally and time expensive. Another user-experienced based approach is multi-criteria, where a set of pre-defined and preevaluated alternatives are assessed, with no assurance of finding the optimal solution because the alternatives search is constrained by the user [18]. Finally, an approach that has shown potential to explore large search spaces in an efficient manner is multi-objective optimisation (MOO). Three basic types of algorithms are used in optimisation problems applied to buildings: enumerative, deterministic, and stochastic [19]. As Nguyen et al. [20] claims, stochastic methods are widely used, being genetic algorithms the most popular method for building optimisation. Other popular methods are Direct Search, Simulated Annealing, and Particle Swarm optimisation [21]. Attia et al. [19] found that MOO methods are normally used during early designs as researchers and practitioners that use optimisation techniques applied $93 \%$ of the cases for new buildings. However, some studies have demonstrated the strength of MOO for retrofit projects [7, 22, 23]. Improvement of the envelope, HVAC equipment, renewable generation, controls, etc., while optimising objectives such as energy savings, occupant comfort, total investment, and life cycle cost has been investigated.

\subsection{The use of exergy analysis for buildings}

However, the aforementioned building energy regulations, modelling tools and optimisation procedures usually only follow the first law of thermodynamics. Energy analysis typically shows similar efficiencies between different systems configurations, so it has significant limitations when it comes to assess the characteristics of energy conversion systems. It also struggles to pinpoint exact locations where inefficiencies are taking place through the whole energy supply chain. As Hammond and Stapleton [24] and Shukuya [25] showed, the majority of the buildings are thermodynamically inefficient, hence have a significant potential for improvement. These inefficiencies are related to the concept of exergy (energy quality or potential to do work), and where unlike energy which is conserved, exergy is exposed to destructions. In the buildings' energy supply chains, these destructions are mainly caused from combustion and heat exchange processes derived from a poor quality match between the supply and the demand. By destroying exergy, useful work that could be useful for other higher quality processes 
(e.g. industrial, transport, and chemical) is wasted. Inefficient and unwise use of resources can significantly impact national energy security [26]. Among all economic sectors in the UK, the building sector has the highest potential to improve its thermodynamic efficiency (Fig. 1), and among end-uses, space conditioning processes present the lowest efficiencies (>6.5\%) [27].

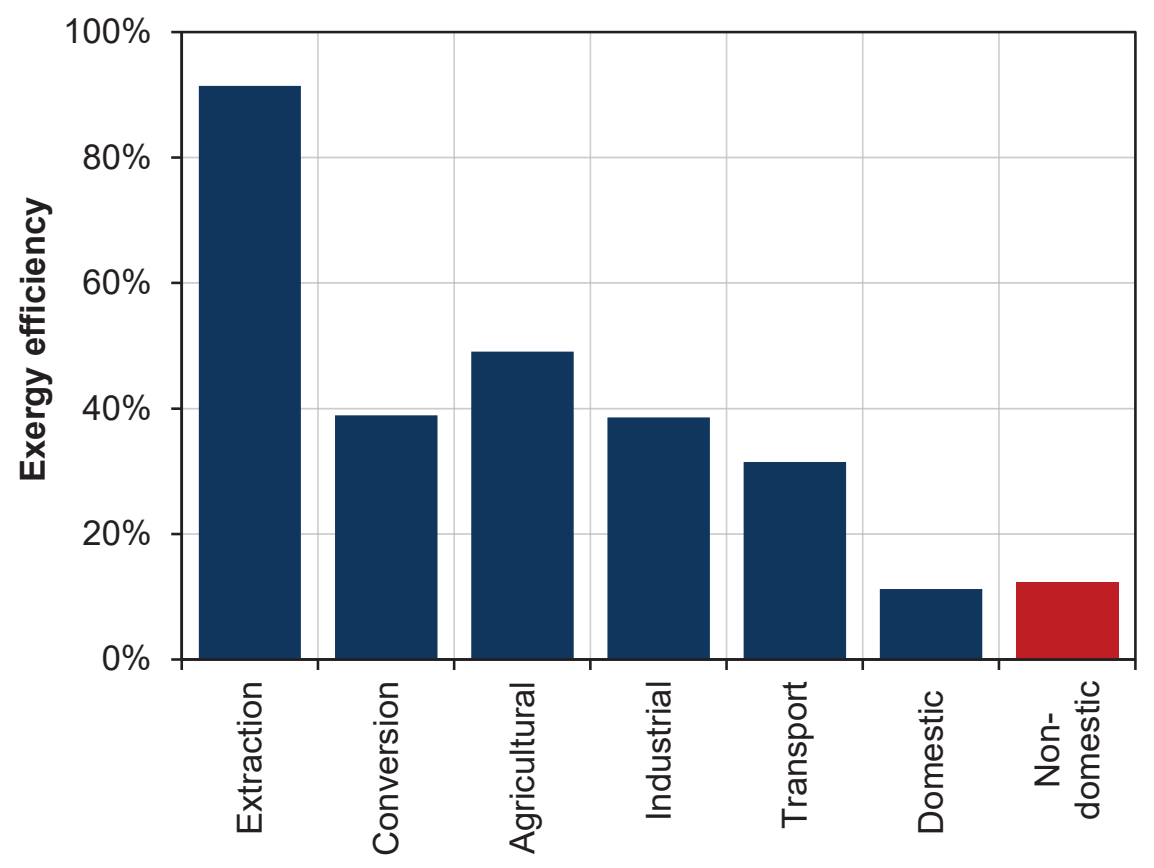

Fig. 1 Exergy Efficiency in different UK sectors. Source: [27].

In recent years, the extent of research and application of exergy analysis in buildings has significantly increased, mainly supported by two IEA Energy in Buildings and Communities Programme Annexes $[28,29]$. The application of exergy analysis has significant potential in the identification of what can be considered unconventional opportunities and the consequent reduction of dependency of high quality fuels. Some research has demonstrated how primary energy input into buildings can be reduced by the application of different principles based on exergy, such as minimizing large temperatures differences, using renewable energy smartly, and considering appropriate passive design measures [30-32]. In addition, a number of simulation tools have been developed with the intention of calculating exergy consumption throughout building energy systems by using a steady-state analysis [33-34]. Nevertheless, as is noted in the final report of the ECB Annex 49, a steady state assessment can only be used to get a first comparison between systems and can contain high uncertainty on the results. To 
overcome the limitation of using a steady-state exergy method on retrofit projects, automated dynamic exergy-based retrofit-oriented modelling tools are required.

Although exergy based multi-objective optimisation are common practice for power plants and chemical processes [35-40] with common optimisation objectives such components cost, fuel cost, exergy destructions, exergy efficiency, and $\mathrm{CO}_{2}$ emissions, in the literature, no optimisation studies were found which uses exergy analysis as a basis for building energy retrofit design. One aim of using exergy analysis for building energy retrofits is to show the exergy interactions when different parts of the energy supply chain are retrofitted. The objective of this paper is to present EXRETOpt (Exergy Analysis Model for Retrofit Optimisation), a retrofit-oriented tool that integrates energy and exergy analysis for buildings with a multi-objective optimisation framework by considering three objectives: energy use, occupant thermal comfort, and exergy destructions (irreversibilities). To understand the differences from an exergy-based scenario by scenario approach against the results of an optimisation process and to test the model capabilities, at first we present a pre-optimisation parametric study considering individual ERMs, such as insulation measures and HVAC systems. Later, we use a robust ERMs database considering more technologies (glazing, lighting, sealing, etc.) to perform a multi-objective optimisation study.

\section{Modelling Framework}

The proposed framework rellies in a recently developed modelling tool which combines two main modules: a) an energy/exergy analysis simulation for buildings, and b) a retrofit optimisation module. The modelling engine is based on different existing tools and modules specifically developed for this research. This framework gives the possibility to study a wide range of measures and optimise retrofit designs under different objective functions such as energy savings, exergy destructions, user thermal comfort, $\mathrm{CO}_{2}$ emissions, return of investment, etc. The simulation workflow and modelling environments are illustrated in Fig. 2. This section will focus on introducing the chosen exergy calculation method and the link between different modules and software. The first two modules regarding building energy model development and calibration will be discussed in the "Case Study" section (Section 4). 


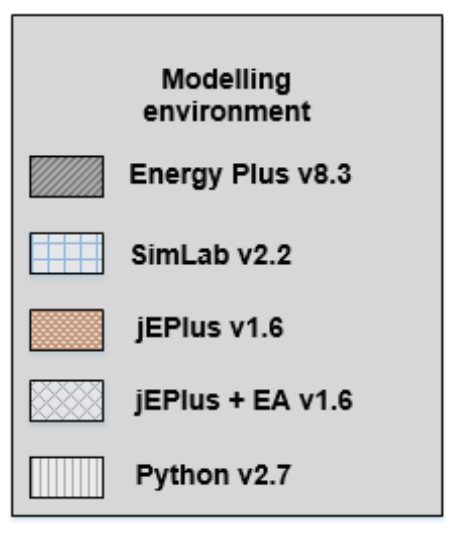

MODULE: Input Data and Baseline Building

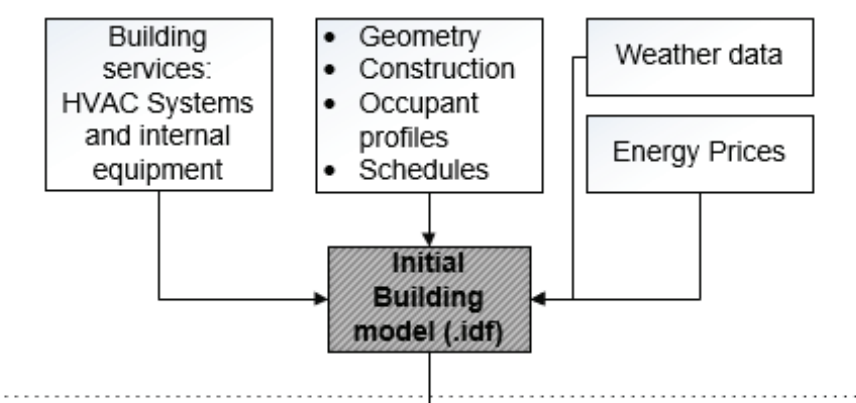

MODULE: Building Model Calibration

Sensitivity and

Uncertainty

Analysis

MODULE: Energy/Exergy analysis, parametric simulations, and retrofit scenarios

\begin{tabular}{l} 
PASSIVE \\
MEASURES \\
- Insulation \\
- Glazing \\
Systems \\
- Sealing \\
- Set-points \\
\hline ACTIVE \\
MEASURES \\
- Generation \\
and Storage \\
- Distribution \\
and emission \\
systems \\
- Lighting \\
- Internal \\
equipment \\
- Improved \\
controls \\
\end{tabular}

Deep energy retrofit :
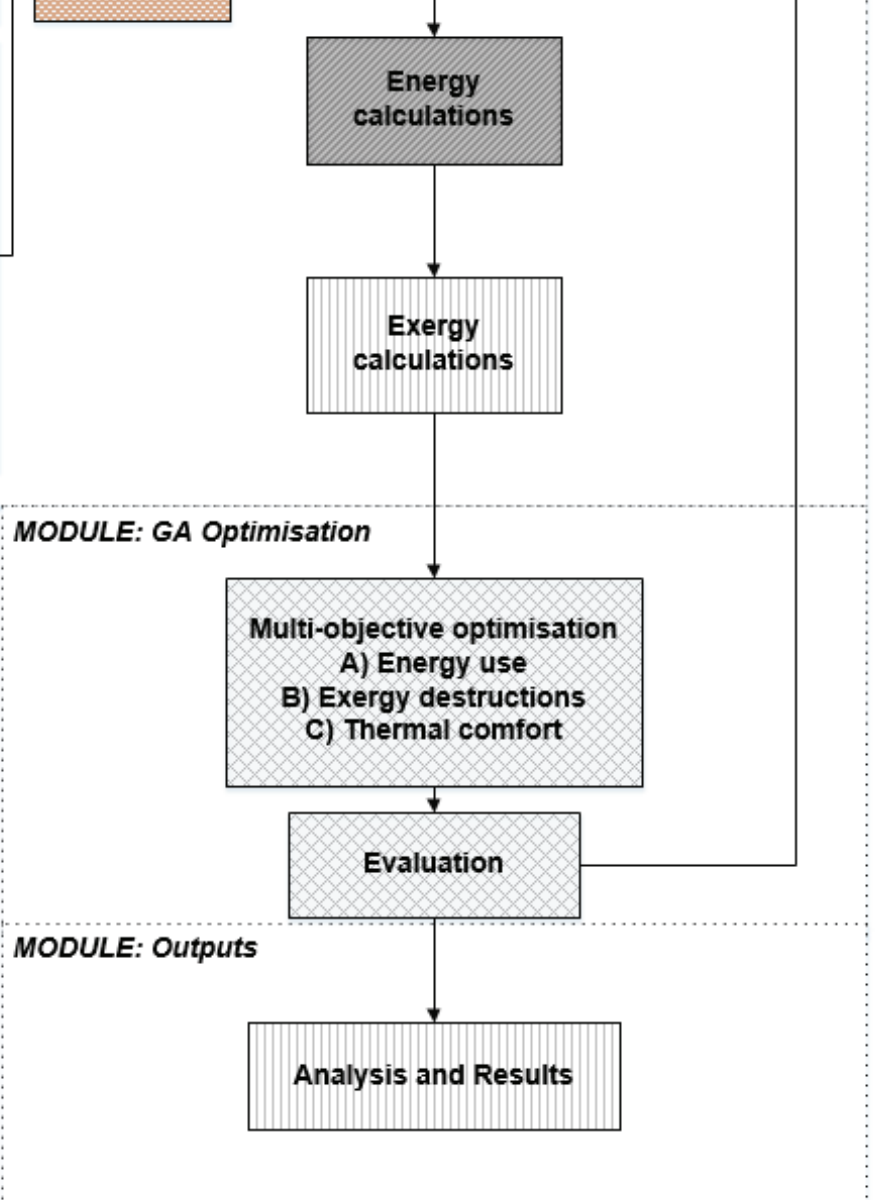

Fig. 2 Workflow overview: Exergy Analysis Model for Retrofit Optimisation (EXRETOpt) 


\subsection{Integrating Exergy analysis and MOO into EnergyPlus}

\subsubsection{Exergy analysis}

The selected exergy method, which has the potential to analyse the whole building energy supply chain is based on the model developed by Schmidt [41] which was further improved in the ECB IEA Annex 49 [29]. For thermal systems (HVAC and DHW), this method follows an input-output approach based on seven different subsystems that are very strongly related to each other, and thus the performance of one subsystem is highly dependent on the other subsystems. In this study, additions to the exergy method were undertaken through implementing exergy analysis on end-uses such as lighting, electric appliances, refrigeration, and catering; thus considering all the possible exergy streams through the building subsystems. Fig. 3 illustrates the abstraction that was made to identify all the building subsystems and streams to be analysed.

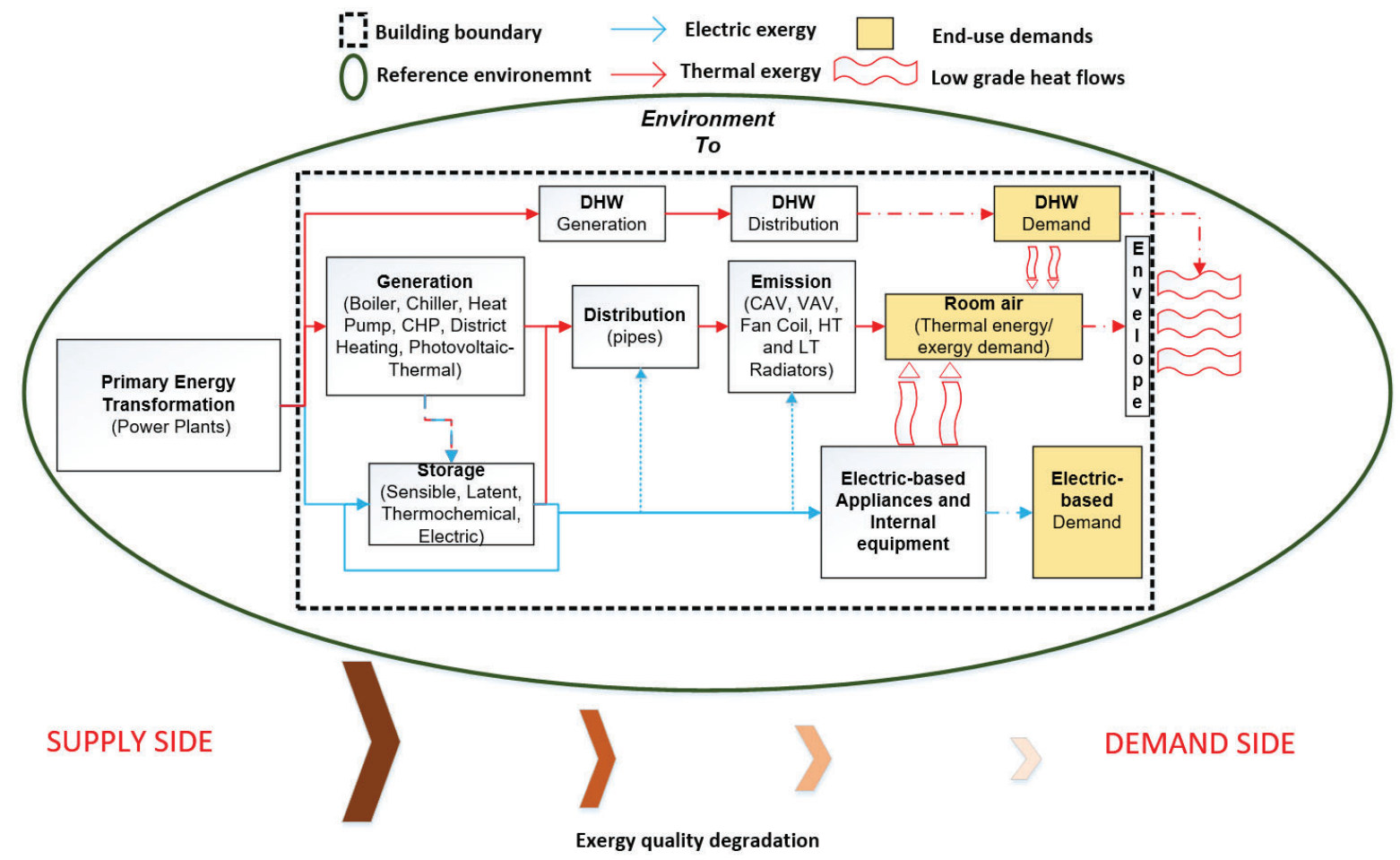

Fig. 3 Energy supply chain and subsystems for exergy calculations. Based on the IEA ECB Annex 49 method calculation [29].

The calculation is performed in the opposite sequence to the demand, starting from the envelope and concluding in the conversion of primary energy. The demand of each subsystem must be satisfied by 
the subsystem before. Unlike energy analysis, exergy demand is not calculated using "exergy balance" equations; but is instead calculated by using the energy balance outputs multiplied by the quality factor, given by the Carnot $^{1}$ equation for thermal exergy. This is one of the reasons why exergy is not a substitute of typical energy analysis and should therefore always be considered complementary to it.

Although the analysis method is well documented in the aforementioned references, in this section a simplification of the method is presented through highlighting the most important equations and some particularities of the current model. Firstly, to calculate the building exergy demand for thermal end uses the detailed exergy demand approach is used [29]. This approach differentiates the demand related to heat $E x_{\text {dem,therm }}$ (Eq. 1) to the demand related to matter $E x_{\text {dem,vent }}$ (Eq. 2). In both the use of the Carnot factor is needed:

$$
\begin{aligned}
E x_{\text {dem,therm,zone ith }}\left(t_{k}\right) & =\sum_{i=1}^{n}\left(E n_{\text {dem,therm ith }}\left(t_{k}\right) *\left(1-\frac{T_{0}\left(t_{k}\right)}{T_{i t h}\left(t_{k}\right)}\right)\right) \\
E x_{\text {dem,vent, }, \text { zone ith }}\left(t_{k}\right) & =\sum_{i=1}^{n}\left(E n_{\text {dem,vent ith }}\left(t_{k}\right) *\left(1-\frac{T_{0}\left(t_{k}\right)}{T_{i t h}\left(t_{k}\right)-T_{0}\left(t_{k}\right)} \ln \frac{T_{i t h}\left(t_{k}\right)}{T_{0}\left(t_{k}\right)}\right)\right)
\end{aligned}
$$

where, $T_{0}$ is the outdoor temperature and $T_{i t h}$ is the average inside temperature of the zones, $E n_{\text {dem,therm }}$ is the energy demand for thermal-based end uses, $E n_{\text {dem,vent }}$ is the energy demand due to ventilation, $t_{k}$ is the time-step, and $n$ is the number of thermal zones analysed.

In a similar manner, exergy demand for refrigeration $E x_{d e m, r e f}$, domestic hot water $E x_{d e m, D H W}$, and cooking $E x_{\text {dem,cooking }}$ can also be calculated using the Carnot factor.

Refrigeration:

$E x_{\text {dem,ref }}\left(t_{k}\right)=Q_{\text {ref }}\left(t_{k}\right) * \operatorname{COP}_{\text {ref }}\left(t_{k}\right)\left(\frac{T_{0}\left(t_{k}\right)}{T_{p_{r e f r}}\left(t_{k}\right)}-1\right)$

\footnotetext{
${ }^{1}$ The Carnot formula sets the limiting value on the fraction of the heat or matter which can be used.
} 
where $Q_{r e f}$ is the energy demand for refrigeration, $C O P_{r e f}$ is the refrigerator's coefficient of performance, and $T_{p_{r e f r}}$ is the refrigerator working temperature.

Domestic Hot Water:

$E x_{d e m, D H W}\left(t_{k}\right)=Q_{D H W}\left(t_{k}\right) * \frac{\eta_{W H}\left(t_{k}\right)}{q_{f u e l}} *\left(1-\left(\frac{T_{0}\left(t_{k}\right)}{T_{p_{W H}}\left(t_{k}\right)-T_{0}\left(t_{k}\right)}\right) * \ln \left(\frac{T_{p_{W H}}\left(t_{k}\right)}{T_{0}\left(t_{k}\right)}\right)\right)$

where $Q_{D H W}$ is the domestic hot water energy demand, $\eta_{W H}$ is the DHW generation system efficiency, $q_{f u e l}$ is the quality factor of the energy source used, and $T_{p_{W H}}$ is the heated water temperature.

\section{Catering:}

Ex dem,cooking $=Q_{\text {cook }}\left(t_{k}\right) * \frac{\eta_{\text {cook }}\left(t_{k}\right)}{q_{\text {fuel }}} *\left(1-\frac{T_{0}\left(t_{k}\right)}{T_{p_{\text {cook }}\left(t_{k}\right)}}\right)$

where $Q_{\text {cook }}\left(t_{k}\right)$ is the cooking energy demand, $\eta_{\text {cook }}$ is the catering equipment efficiency, and $T_{p_{\text {cook }}}\left(t_{k}\right)$ is the cooking temperature.

As electricity has similar energy and exergy contents, the majority of electric-based equipment such as fans, pumps, lighting, computers, and motors were considered to have the same exergy efficiency as their energy counterpart $\left(\psi_{\text {elec }} \approx \eta_{\text {elec }}\right)$ and therefore the same exergy consumption. Hence, to calculate the electrical exergy demand $E x_{\text {dem,elec, ith }}$ the following formula was used:

$E x_{\text {dem,elec,ith }}\left(t_{k}\right)=E n_{\text {dem,elec }, \text { ith }}\left(t_{k}\right) * F_{q, \text { elec }}$

where $E n_{\text {dem,elec,ith }}$ is the energy demand for the ith electric-based end use equipment, and $F_{q, e l e c}$ is the quality factor of electricity. The values in Table 1 were used for the analysis of electric-based equipment: 
Table 1 Exergy efficiency values for electric-based devices [42]

\begin{tabular}{ccc}
\hline Equipment & $\begin{array}{c}\text { Energy Efficiency } \\
(\mathbf{\%})\end{array}$ & $\begin{array}{c}\text { Exergy efficiency } \\
(\mathbf{\%})\end{array}$ \\
\hline Motors & $80-87$ & $80-87$ \\
Fuel cell system & 33 & 33 \\
CHP & 74 & 31 \\
Electric battery (lead-acid) & $75-85$ & $75-85$ \\
Pumps & 70 & 70 \\
Fans & 90 & 90 \\
Lighting fluorescent and LED & 20 & 20 \\
Electric-based catering & 85 & 50 \\
Internal/office equipment & 70 & 70 \\
\hline
\end{tabular}

Finally, to obtain the total exergy demand at the building level $E x_{\text {dem,bui }}$ all previous calculated demands are added as follows:

$E x_{\text {dem }, \text { bui }}=\sum E x_{\text {dem, end }}$ use, ith

where $E x_{\text {dem,end }}$ use is the exergy demand for each end-use.

\section{Primary Exergy Input and Irreversibilities calculation}

After demands are calculated, the model proceeds to calculate exergy destructions at each subsystem level. As can be seen in Fig. 3, the subsystem analysis is more detailed for thermal based end uses, where the energy supply chain is divided in 7 components (PET, generation, storage, distribution, emission, room, and envelope). On the other hand, for DHW, 4 subsystems are considered (PET, generation, distribution, demand); while for electric based equipment only 3 subsystems are considered (PET, distribution, demand). To analyse exergy input at the primary generation subsystem $\left(E x_{\text {prim }}\right)$ and distinguish the impact of using different types of energy sources, equation (8) was used:

$E x_{\text {prim }}\left(t_{k}\right)=\sum_{i}\left(\frac{E n_{\text {gen }, i}\left(t_{k}\right)}{* \eta_{\text {gen }, i}\left(t_{k}\right)} * F_{p, \text { source }, i} * F_{q, \text { source }, i}\right)+\left(\right.$ Ex $\left._{\text {dem, elec }, \text { ith }}\left(t_{k}\right) * F_{p, \text { elec }}\right)$ 
where, $E n_{\text {gen }}$ is the total energy used by the building HVAC/DHW generation systems (chiller, boiler, $\mathrm{CHP}$, etc.), $\eta_{g e n}$ is the system efficiency, $F_{p, \text { source }}$ and $F_{q, \text { source }}$ is the is the UK primary energy factor [43] and fuel quality factor [29], respectively, $E x_{\text {dem,elec,ith }}$ is the exergy demand for electric based equipment, and $F_{p, e l e c}$ is the primary energy factor for electricity. Fuel primary energy factors and quality factors used in this study are shown in Table 2.

Table 2 Primary Energy Factors and Quality Factors by energy sources [43]

\begin{tabular}{ccc}
\hline Energy source & $\begin{array}{c}\text { Primary energy factor } \\
\left(\boldsymbol{F}_{\boldsymbol{p}}\right)\end{array}$ & $\begin{array}{c}\text { Quality factor } \\
(\mathbf{F W h} / \mathbf{k W h})\end{array}$ \\
\hline (kWhex/kWhen) \\
\hline Natural gas & 1.11 & 0.94 \\
Electricity (Grid supplied) & 2.58 & 1.00 \\
District Energy ${ }^{2}$ & 1.11 & 0.94 \\
Oil & 1.07 & 1.00 \\
Biogas (Wood pellets) & 0.20 & 1.20 \\
\hline
\end{tabular}

Finally, an important indicator in this research is 'total exergy destructions' $E x_{\text {dest }}$. When the energy supply passes through the energy supply chain, exergy destructions are expected throughout all the subsystems. These are dependent on factors such as the building envelope or the systems components characteristics. Although the 'primary energy transformation subsystem' is located outside the building boundary, the exergy method used in this study also considers the destructions at this stage. Within this framework it is possible to distinguish many sources (e.g. electricity, natural gas, and district energy), and external supplies (gas, oil, renewables), which gives a more robust understanding of the impact of different primary energy sources used for buildings and its systems. This indicator is important as it is used as one of the optimisation objectives. This was obtained by subtracting the primary exergy supplied minus the exergy demanded by the building as follows:

$E x_{\text {dest }}=E x_{\text {prim }}-E x_{\text {dem,bui }}$

\footnotetext{
${ }^{2}$ The District system was assumed to be run by a single-effect indirect-fired absorption chiller with a coefficient of performance (COP) of 0.7 .
} 
where $E x_{\text {prim }}$ and $E x_{d e m, b u i}$ are the total primary exergy supplied and total building exergy demand, respectively. A limitation of this analysis is that only thermal exergy is considered, neglecting the effect of chemical and mechanical exergy.

\section{The reference environment}

Exergy calculations are highly dependent on the choice of the reference environment. This is determined with a preliminary analysis to identify the environment able to act as entropy-disposal sink. An essential characteristic of the reference environment is that it has to be irreversibilities-free, where all the major exergy destructions should occur on the system or process being analysed [44]. The majority of studies in this field perform steady state calculations using monthly or seasonal average temperatures. For this work, hourly external temperatures given by the TMY2 weather files were taken as the reference environment, which allows the model to perform 1-h step calculations.

\subsubsection{Coupling Exergy analysis with EnergyPlus}

The open source software tool EnergyPlus [10] was selected as the calculation tool for first law analysis. While EnergyPlus in its original format is not capable of performing exergy analysis, its characteristics allow users to easily develop external add-ons. EnergyPlus is able to deliver the detailed inputs needed for the dynamic exergy analysis such as building energy demand, primary energy use, indoor and outdoor temperatures, and HVAC/DHW working fluid temperatures, mass, and enthalpies at any system location. For the linking of the selected exergy method with EnergyPlus the jEPlus 1.6.0 software environment [45] was used. JEPlus is an open source tool created to manage complex parametric studies. The latest versions provide users with the ability to use Python scripting for running own-made processing scripts. Miller et.al [46] outlined the capabilities of using Python for building energy performance simulation and analysis, where adaptability, reliability, and calculation speed were the main advantages. For the EXRETOpt model, Python 2.7 programming language was used for the exergy building performance simulation. The developed scripts manipulate a series of outputs obtained from EnergyPlus, then a new set of thermodynamic equations are applied to finally provide a new set of outputs for jEPlus to handle. The code reads any selected hourly outputs from EnergyPlus and creates new spreadsheets with exergy indicators. The model is capable of providing $250+$ energy, exergy, environmental, and economic indicators. Communication between EnergyPlus and the Python- 
based exergy model is mainly supported through the use of jEPlus .rvx files (extraction files), which allows the manipulation and handling of data back and forth between EnergyPlus, Python, and jEPlus. This process, shown in Fig.4, is embedded in the "MODULE: Energy/Exergy analysis, parametric simulations, and retrofit scenarios" in the simulation framework previously illustrated in Fig.2.

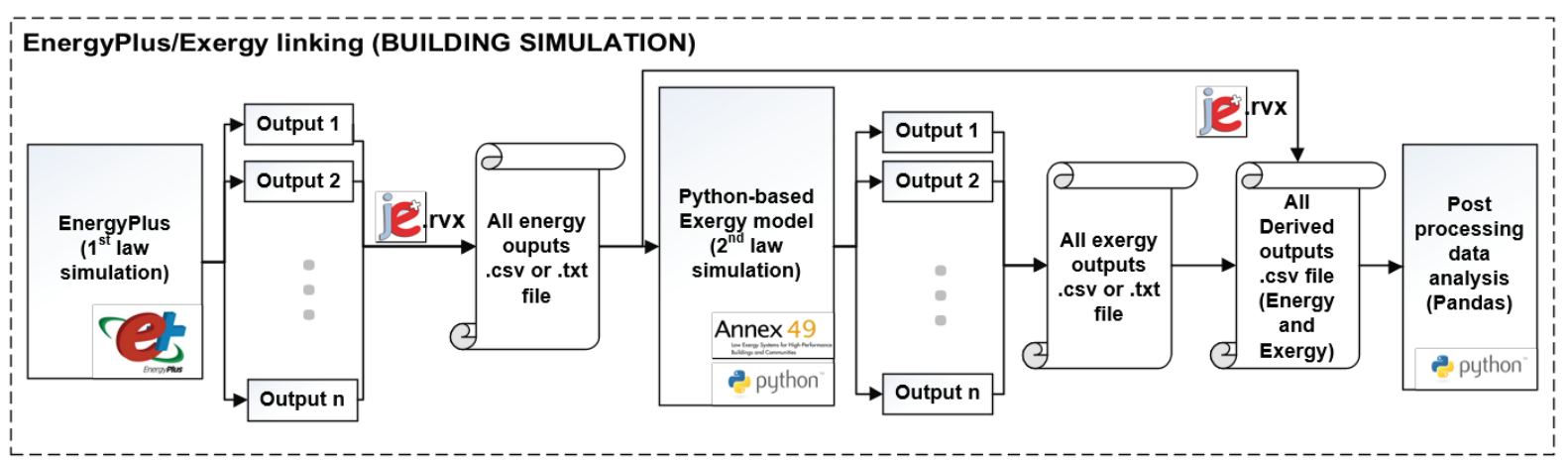

Fig. 4 Flow of Energy/Exergy co-simulation using EnergyPlus, Python scripting and jEPlus

For the calibration and verification of the exergy analysis method, model outputs were compared to results obtained from the steady-state Annex 49 pre-design tool. This comparison should be considered with caution as dynamic simulation results can vary greatly from steady state assessments due to variations in the reference environment.

\subsubsection{Retrofit scenarios and parametric simulation}

Prior to conducting the optimisation problem analysis, a retrofit module that considers all the variables that will be changed to the defined baseline models was developed. Based on this approach, different retrofit measures were designed at each level of the building energy supply system and building envelope (Table 3 and Table 4). This module encompasses a variety of retrofit measures (parameters) typically applied to UK non-domestic buildings [47]. For example, for the case of the insulation thickness, the values were taken from current available products in the UK market $[48,49]$, as such each technology has a different thickness. 
Table 3 HVAC systems considered in the optimisation project.

\begin{tabular}{|c|c|c|}
\hline $\mathbf{P}$ & HVAC Systems & Emission systems \\
\hline$X^{1}$ & $\begin{array}{ll}\text { - } & \text { Condensing Gas Boiler (n:0.95) + } \\
& \text { Water-based Chiller (COP: 3.2) } \\
\text { - } & \text { Biomass Boiler (n:0.90) + Water- } \\
& \text { based Chiller (COP: 3.2) } \\
\text { - } & \text { Air Source Heat Pump (COP: } 3.4) \\
\text { - } & \text { District system (CHP with absorption } \\
& \text { chiller COP: 0.7) } \\
\text { - } & \text { Ground Source Heat Pump (COP: 4.6) }\end{array}$ & $\begin{array}{ll}: & \text { CAV } \\
- & \text { VAV } \\
- & \text { VRF } \\
\text { - } & \text { Wall } \\
\text { - } & \text { Underfloor } \\
- & \text { Wall+Underfloor }\end{array}$ \\
\hline
\end{tabular}

Table 4 Non-HVAC retrofit measures considered in the optimisation project.

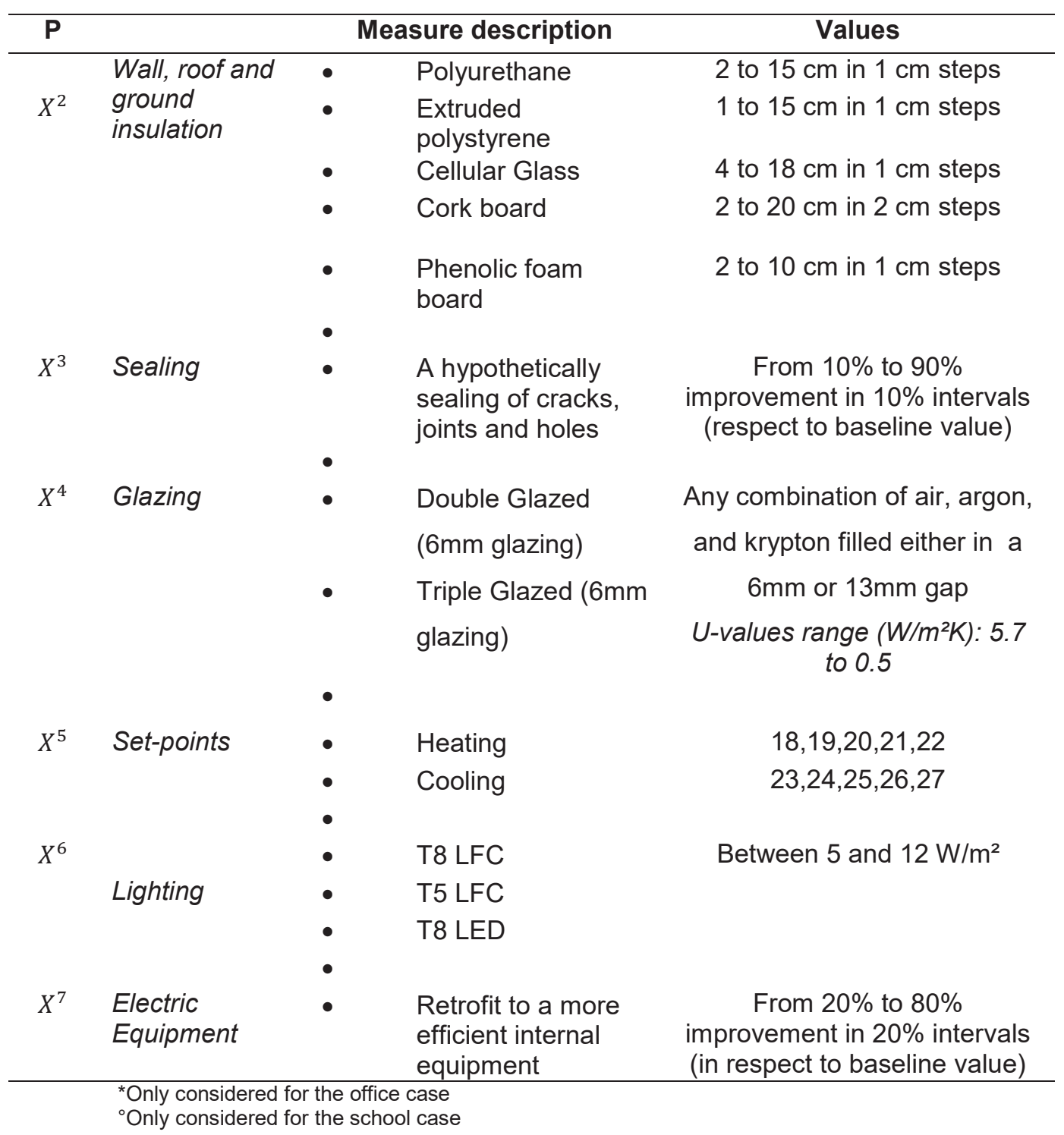

As retrofit models involve the selection of several modelling parameters, and to be able to handle different systems designs, the definition must be made by using EnergyPlus Macro function. The 
function allows for the creation of compact .idf files that can represent each measure. jEPlus will then pick the files and put them into the main building model to then 'call on' EnergyPlus for final simulation. jEPlus has facilitated the coupling by encoding retrofit measures into 'genes', expressing new genes as new building models.

\subsubsection{Multi objective optimisation module with NSGA-II}

To merge the 'energy/exergy analysis and retrofit module' with a multi-objective algorithm, a link to jEPlus + EA [50] was developed. The optimisation process is embedded in the "Module: GA Optimisation" shown in Fig. 2. In the modelling process, once jEPlus has handled the simulation files and provided the final outputs from the energy/exergy model, the optimisation module takes over. This communication was coupled with the help of the .rvx file (jEPlus extraction file), where objective functions as well as constraints have to be defined. The tool has the ability to tackle multi-objective optimisation by using a Non-Dominated Sorting Genetic Algorithm (NSGA-II). This stochastic method imitates the evolution of species described by Charles Darwin. The algorithm works with a set of individuals, which can represent possible solutions of the problem. In this case, the individuals are the different building models previously created. Each of these individuals (or chromosomes) are composed by a set of genes, in this case the different building parameters or retrofit measures $\left(\left\{X^{1}, X^{2}, \ldots, X^{7}\right\}\right.$. The selection of individuals is undertaken through the application of the "survival of the fittest" principle [51], which selects the building models that are closer to the objective functions. jEPlus+EA then ranks chromosomes and calculates a uniqueness value related to the distance between each solution and its two closest neighbours. The 'genes' located in the best chromosomes often go through to the next generation, so similar models will be evaluated. For more variability among models, other recombination processes such as crossover and mutation take place to drive better solutions to the next generation by avoiding the algorithm's focus on only a limited number of parameters. The detailed algorithm process as well as the modelling environments are shown in Fig. 5. 

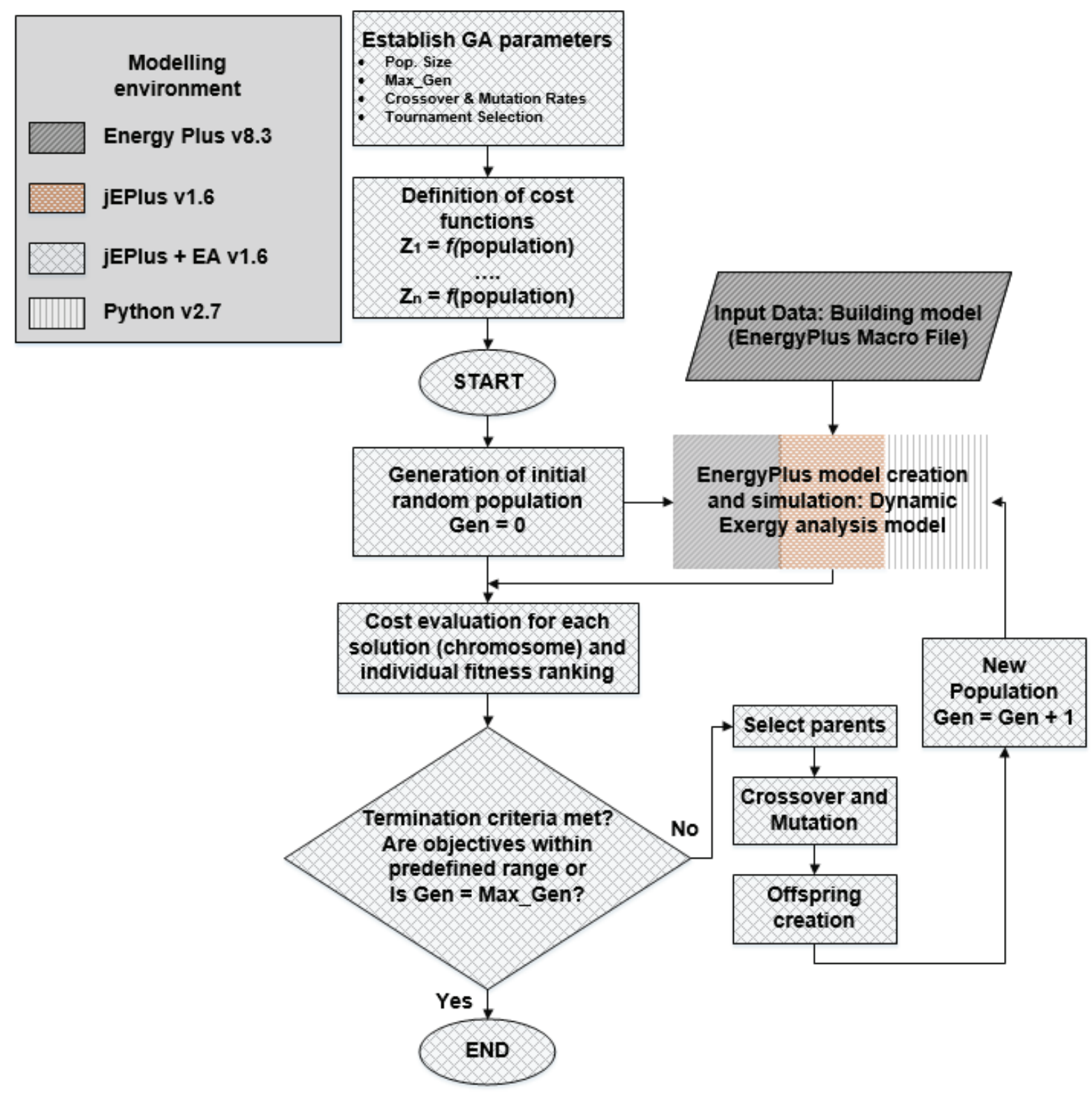

Fig. 5 Genetic algorithm optimisation applied to the EXRETOpt tool.

\subsubsection{Objective functions}

In general, an energy optimisation problem requires at least two conflicting problems. In this study three objectives that have to be satisfied simultaneously were investigated. These were the increase of exergy efficiency (or reduction of exergy destructions), reduction of building energy use, and the increase of occupant thermal comfort hours. The minimization of energy use can be strongly related to exergy use but may have different implications on energy sources with different quality levels, where destructions could be bigger for higher quality sources depending on the energy conversion 
technologies. Hence, the optimisation problem was formulated as follows: given a 7-dimensional decision variable vector $x=\left\{X^{1}, X^{2}, X^{3}, X^{4}, X^{5}, X^{6}, X^{7}\right\}$ in the solution space $X$, find the vector(s) $x^{*}$ that minimizes a given set of three objective functions: $Z\left(x^{*}\right)=\left\{Z_{1}(\mathrm{x} *), Z_{2}(\mathrm{x} *), Z_{3}(\mathrm{x} *)\right\}$. The objective functions being:

a) Building annual energy use:

$Z_{1}(x) \min =E U I \quad,\left[\mathrm{kWh} / \mathrm{m}^{2}\right.$-year $]$

b) Occupant discomfort hours:

$Z_{2}(x) \min =(|P M V|>0.7)^{3}$, [Hours],

c) Building annual exergy destructions:

$Z_{3}(x) \min =\left\{\sum_{i}\left[\frac{E_{\text {gen }, i}\left(t_{k}\right)}{\eta_{\text {gen }, i}\left(t_{k}\right)} * F_{p, \text { source }, i} * F_{q, \text { source }, i}\right]-\left[F_{q, \text { building }} * \sum_{i} Q_{i}\left(t_{k}\right)\right]\right\},\left[\mathrm{kWh} / \mathrm{m}^{2}\right.$-year $]$

No constraints in the building parameters or in the modelling outputs were considered in this paper. As there is usually no single solution that can satisfy all the objectives in $\mathrm{MOO}$, a Pareto front was obtained. All these solutions were equally satisfactory unless the decision maker put more importance on one objective than the others. Regardless of this, the main goal of the tool is to find as many of optimal solutions as possible.

\footnotetext{
3 Given by [52] ASHRAE. ANSI/ASHRAE Standard 55-2004. Thermal Environmental Conditions for Human Occupancy. American Society of Heating, Refrigerating and Air-conditioning Engineers; 2004. It shows the amount of uncomfortable hours for each zone under the criteria of assuming both summer and winter clothes ( $0.5 \mathrm{Clo}$ and $1.0 \mathrm{Clo}$ respectively). These are based on whether the humidity ratio and the operative temperature are within region.
} 


\section{Case Study}

\subsection{Building Archetypes}

The EXRETOpt model was applied to two archetypal UK non-domestic buildings-a primary school and an air-conditioned (A/C) office building- which belong to two-subsectors that in the UK have an annual energy demand of more than 200 PJ [53]. These archetypes were selected to allow for comparison and to perform analysis for both heating and cooling cases (for the office building). These archetypes models (Fig. 6), were developed based on an extensive review of relevant literature [54-56] combined with statistical analysis from data sources. The main characteristics of each can be described as follows:

Primary School Archetype: The form and geometry of the archetype is based on the baseline designs for primary schools developed by the UK Education Funding Agency [57]. These designs demonstrate good practice and are based on the departmental guidelines for area planning. The simulation model consists of a 14 thermal zone building distributed over two storeys. The largest proportion of the floor area is occupied by classrooms, staff offices, laboratories, and the main hall. Other minor zones include corridors, bathrooms, and other common rooms. Heating is provided by means of conventional gas boiler and high temperature radiators $\left(80^{\circ} \mathrm{C} / 60^{\circ} \mathrm{C}\right)$ with no heat recovery.

Office Archetype: An open-plan office model based on 6 thermal zones over three storeys was developed based on the UK offices archetypes developed by Korolija \& Marjanovic-Halburd [55]. As previous analysis of the model showed high homogeneity between areas, fewer thermal zones were analysed compared to the primary school archetype. This archetype consists of only office areas and common areas (including bathrooms and kitchen) on each of the three floors. The HVAC system includes a gas boiler for heating and an air-based chiller (COP: 2.0) to meet cooling demands. The air distribution system is composed of Constant Air Volume (CAV) fan-coil units.

The minimum fabric thermal values from the 1985 UK Building Regulations [58] were used for the building fabric elements for both archetypes. All other model variables such as occupancy patterns, thermostat temperatures, infiltration, and interior equipment were based on CIBSE guides [59]. The weather data file, and thus the reference temperature for exergy analysis, was based on the LondonGatwick TMY2 file. 
Primary School

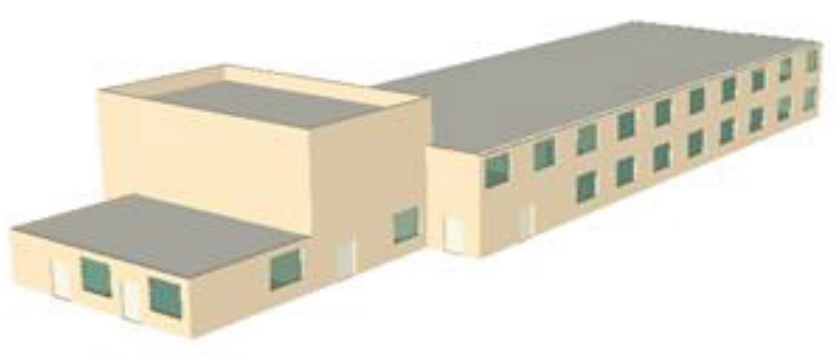

Office

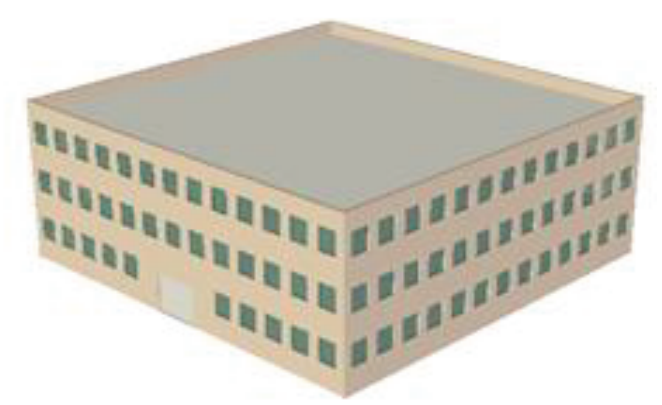

Fig. 6 Computer generated 3D model of the UK primary school and office building archetypes

\subsection{Building energy model calibration}

As modelling process includes assuming inputs that are either unknown or hard to measure, this can therefore have a significant impact on outputs. To assess the impact of these uncertainties related to what were considered important input variables on the total predicted annual energy use [60], a comprehensive sensitivity and uncertainty analysis (SA\&UA) was performed using SimLab 2.2 [61]. SA\&UA is a common method for calibration of baseline building designs and for exploration of retrofit measurers where payback periods can vary depending on the input variable assumptions made [62].

To calibrate the models, 8 significant parameters were analysed: building orientation, envelope thermal conductivity, air tightness, occupant density, set point values, HVAC system efficiency, and lighting and equipment power density. For parameters where limits were hard to measure normal distributions were considered for the analysis. The Latin Hypercube Sampling method was used to create 200 models for each building followed by a Monte Carlo Analysis to obtain sensitivity and uncertainty results. To ensure that the predicted energy use for both models was realistic, values obtained from the analysis of thousands of Display Energy Certificates (DEC) of non-domestic buildings located in England and Wales were used for reference [63-65]. The archetype models were calibrated with values representing the top $25 \%$ performing buildings in the subsector. For the primary school archetype these values were $42 \mathrm{kWh} / \mathrm{m}^{2}$ for electricity and $107 \mathrm{kWh} / \mathrm{m}^{2}$ for gas, while for the office archetype these were $105 \mathrm{kWh} / \mathrm{m}^{2}$ for electricity and $87 \mathrm{kWh} / \mathrm{m}^{2}$ for gas. The entire search space simulation and calibrated baseline model (in red) for both buildings is illustrated in Fig. 7. 

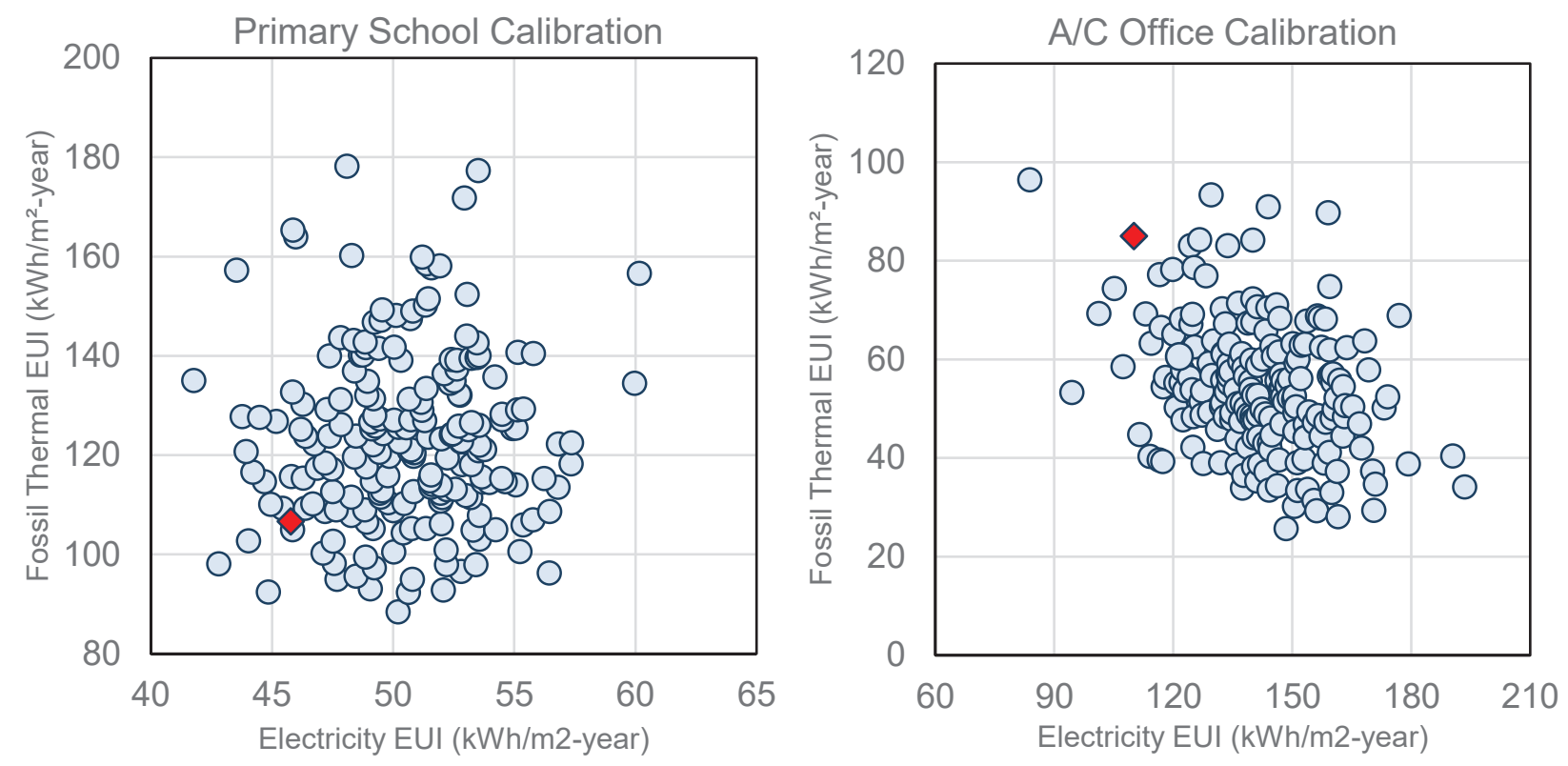

Fig. 7 Simulation cases from Latin Hypercube Sampling. In red the selected calibrated building

The baseline building characteristics for both energy models are listed in Table 5. 
Table 5 Baseline characteristics for the primary school and A/C office archetypes.

\begin{tabular}{|c|c|c|}
\hline Baseline characteristics & Primary School & A/C Office \\
\hline Year of construction & 1980s & 1980s \\
\hline Number of floors & 2 & 3 \\
\hline Floor space $\left(m^{2}\right)$ & 1990 & 2590 \\
\hline Thermal Zones & 14 & 6 \\
\hline Orientation $\left(^{\circ}\right)$ & 245 & 255 \\
\hline Infiltration (ach) & 0.58 & 0.78 \\
\hline \multirow[t]{2}{*}{ Exterior Walls } & $\begin{array}{l}\text { Cavity wall-Brick walls } 100 \mathrm{~mm} \\
\text { brick with } 25 \mathrm{~mm} \text { air gap }\end{array}$ & $\begin{array}{l}\text { Cavity wall-Brick walls } 100 \mathrm{~mm} \\
\text { brick with } 25 \mathrm{~mm} \text { air gap }\end{array}$ \\
\hline & U-value $=0.34\left(\mathrm{~W} / \mathrm{m}^{2} \mathrm{~K}\right)$ & U-value $=0.50\left(\mathrm{~W} / \mathrm{m}^{2} \mathrm{~K}\right)$ \\
\hline \multirow[t]{2}{*}{ Roof } & $200 \mathrm{~mm}$ concrete block & $200 \mathrm{~mm}$ concrete block \\
\hline & U-value $=0.35\left(\mathrm{~W} / \mathrm{m}^{2} \mathrm{~K}\right)$ & U-value $=0.55\left(\mathrm{~W} / \mathrm{m}^{2} \mathrm{~K}\right)$ \\
\hline \multirow[t]{2}{*}{ Ground floor } & $150 \mathrm{~mm}$ concrete block & $150 \mathrm{~mm}$ concrete block \\
\hline & U-value $=0.53\left(\mathrm{~W} / \mathrm{m}^{2} \mathrm{~K}\right)$ & U-value $=0.53\left(\mathrm{~W} / \mathrm{m}^{2} \mathrm{~K}\right)$ \\
\hline \multirow[t]{2}{*}{ Windows } & Double-pane clear (5mm thick) & Double-pane clear (5mm thick) \\
\hline & U-value $=3.66\left(\mathrm{~W} / \mathrm{m}^{2} \mathrm{~K}\right)$ & U-value=3.66 $\left(\mathrm{W} / \mathrm{m}^{2} \mathrm{~K}\right)$ \\
\hline Glazing ratio & $28 \%$ & $41 \%$ \\
\hline HVAC System & $\begin{array}{l}\text { Gas-fired boiler } 419 \mathrm{~kW} \\
\quad \eta=83 \% \\
\text { No cooling system }\end{array}$ & $\begin{array}{l}\text { Gas-fired boiler } 603 \mathrm{~kW} \\
\eta=70 \% \\
\text { Air-based Chiller } 205 \mathrm{~kW} \\
\text { COP }=2.0\end{array}$ \\
\hline \multirow[t]{2}{*}{ Emission system } & Heating: HT Radiators $90 / 70^{\circ} \mathrm{C}$ & Heating: CAV $80 / 50^{\circ} \mathrm{C}$ \\
\hline & Cooling: Natural ventilated & Cooling: CAV $7 / 12^{\circ} \mathrm{C}$ \\
\hline Heating Set Point $\left({ }^{\circ} \mathrm{C}\right)$ & 19.6 & 22.3 \\
\hline Cooling Set Point $\left({ }^{\circ} \mathrm{C}\right)$ & -- & 25.3 \\
\hline Occupancy (people/m²)* & 2.2 & 9.3 \\
\hline Equipment $\left(W / m^{2}\right)^{*}$ & 4.3 & 10.1 \\
\hline Lighting level $\left(W / m^{2}\right)^{*}$ & 12.7 & 12.0 \\
\hline EUI electricity $\left(\mathrm{kWh} / \mathrm{m}^{2}-\mathrm{y}\right)$ & 45.8 & 110.9 \\
\hline EUI gas $\left(k W h / m^{2}-y\right)$ & 106.7 & 84.9 \\
\hline Thermal discomfort (hours) & 1193 & 1434 \\
\hline CO2 emissions (Ton) & 185.2 & 195.5 \\
\hline
\end{tabular}

*Just for main areas. School: Classrooms and Staff offices. A/C office: Open plan office space

\section{Results and Analysis}

\subsection{Baseline results}

Baseline outputs were obtained for both models. The school archetype EUI (one of the optimisation objectives) was $152.5 \mathrm{kWh} / \mathrm{m}^{2}$-year; with gas as the main energy source $(70.0 \%)$. By end-use, heating represented $48.2 \%$ of the total energy demand, followed by DHW $(21.8 \%)$ and lighting $(17.5 \%)$. In the 
case of the office, the EUI was $197.5 \mathrm{kWh} / \mathrm{m}^{2}$-year with similar demands for gas and electricity (gas: $57 \%$, electricity: $43 \%)$. The main end-use was heating (36.7\%) followed by interior equipment $(23.0 \%)$ and lighting (21.8\%). The results show different end-use patterns between building types, mainly due to the cooling demand in summer months for the office archetypes. A monthly breakdown by end-use can be seen in Fig. 8.
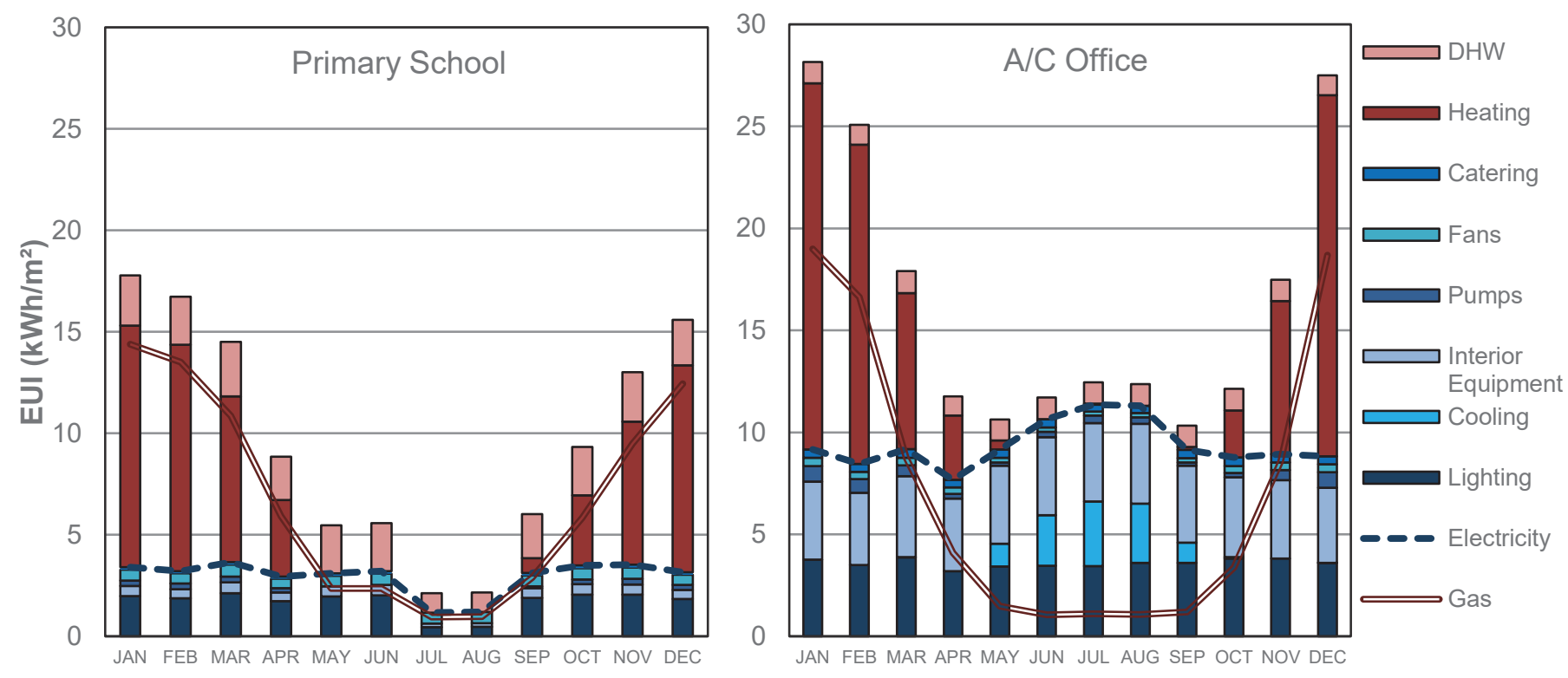

Fig. 8 Monthly Energy Use Indicators by end-uses for the baseline models. In red colours gas based enduses. In blue colours electricity based end-uses.

The second objective, the non-comfortable hours, was to be 1,193 hours per year for the school archetype. This considered all the main occupied zones (classrooms, offices and common areas) as well as evening activities, summer time activities, and staff working hours. For the office archetype this was found to be 1,439 hours.

The normalized exergy destructions (considering HVAC, DHW, and electric-based equipment) were 207.3

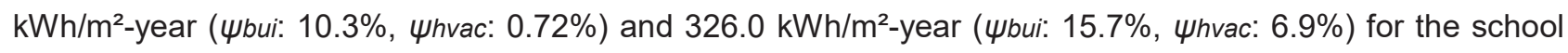
and office, respectively. These results express the actual thermodynamic efficiency of the buildings and provide more insight on how exergy diminishes inside the energy supply chain. To illustrate the advantages of a dynamic exergy modelling, Fig. 9 shows the primary school archetype HVAC hourly exergy destructions for a winter design day disaggregated by subsystem. The largest destructions are caused by and occur at the 
generation subsystem (gas fired boiler) due to the high-temperature combustion process that takes place. In the summer, as no mechanical cooling is required, exergy destructions were zero.

\section{Primary School: HVAC Heating Exergy Destructions 21-Feb}

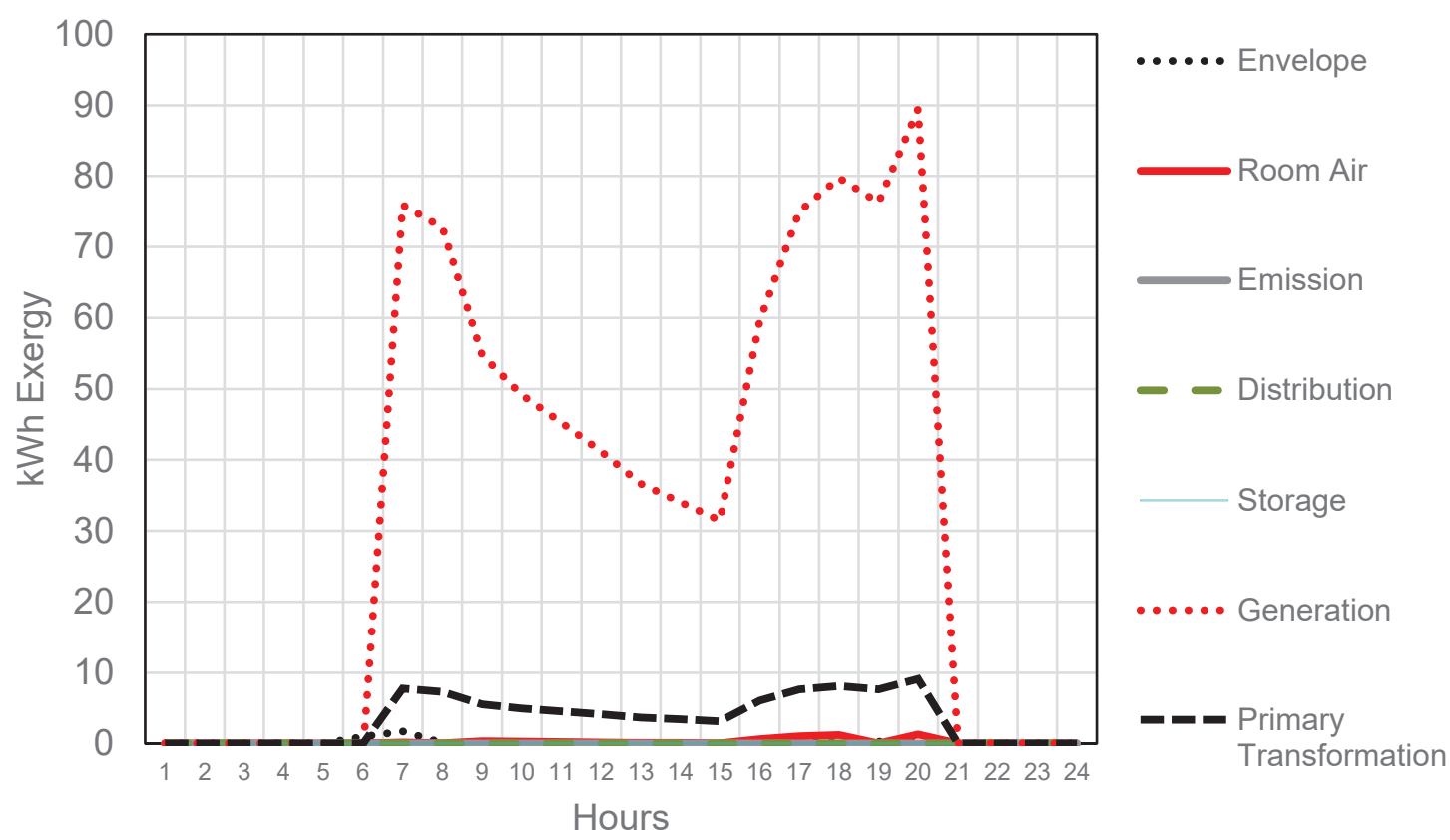

Fig. 9 Primary school: Winter Design Day. Baseline Exergy destructions by HVAC subsystems

Fig. 10 and Fig. 11 illustrate the office archetype HVAC hourly exergy destructions for the winter and summer design days, respectively. A markedly different pattern can be seen in the two seasons; while the main destructions in colder months are located in the generation subsystem (boiler) during the summer the main destructions shift to the 'Primary Energy Transformation', where the conversion process from natural energy sources to electricity produces the highest exergy destructions in the supply chain. In this case, the use of a high quality source (electricity) for a low quality demand such as cooling process in a temperate climatic is highly penalised by exergy analysis. As can be seen in Fig. 11, the dotted line representing the envelope destructions are below zero, this indicates that the building has exergy that has to be removed from within it to the environment. This usually occurs when a cooling process is required even when the outside temperature is below the room set point temperature. 


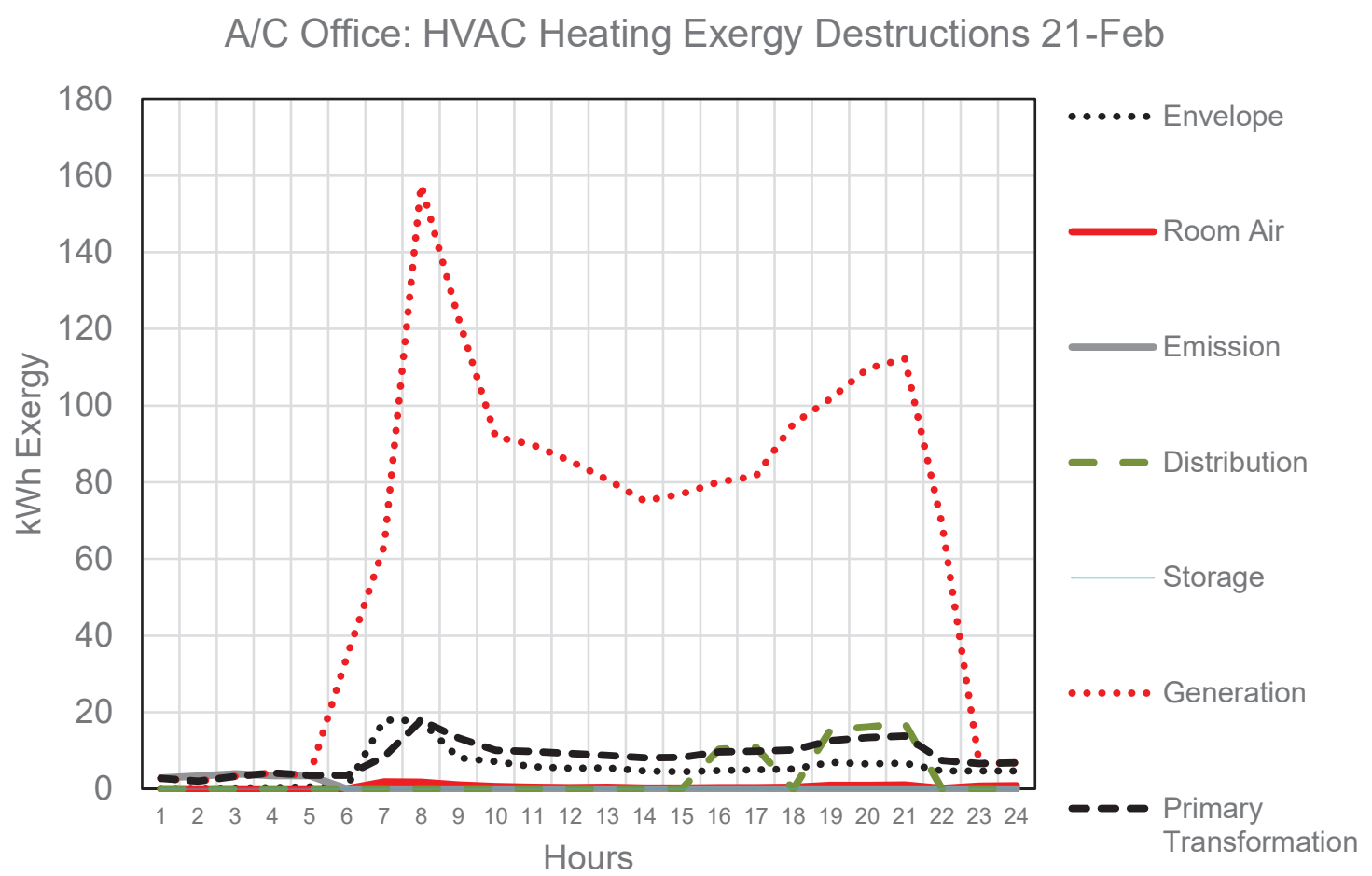

Fig. 10 A/C office: Winter Design Day. Baseline Exergy destructions by HVAC subsystems

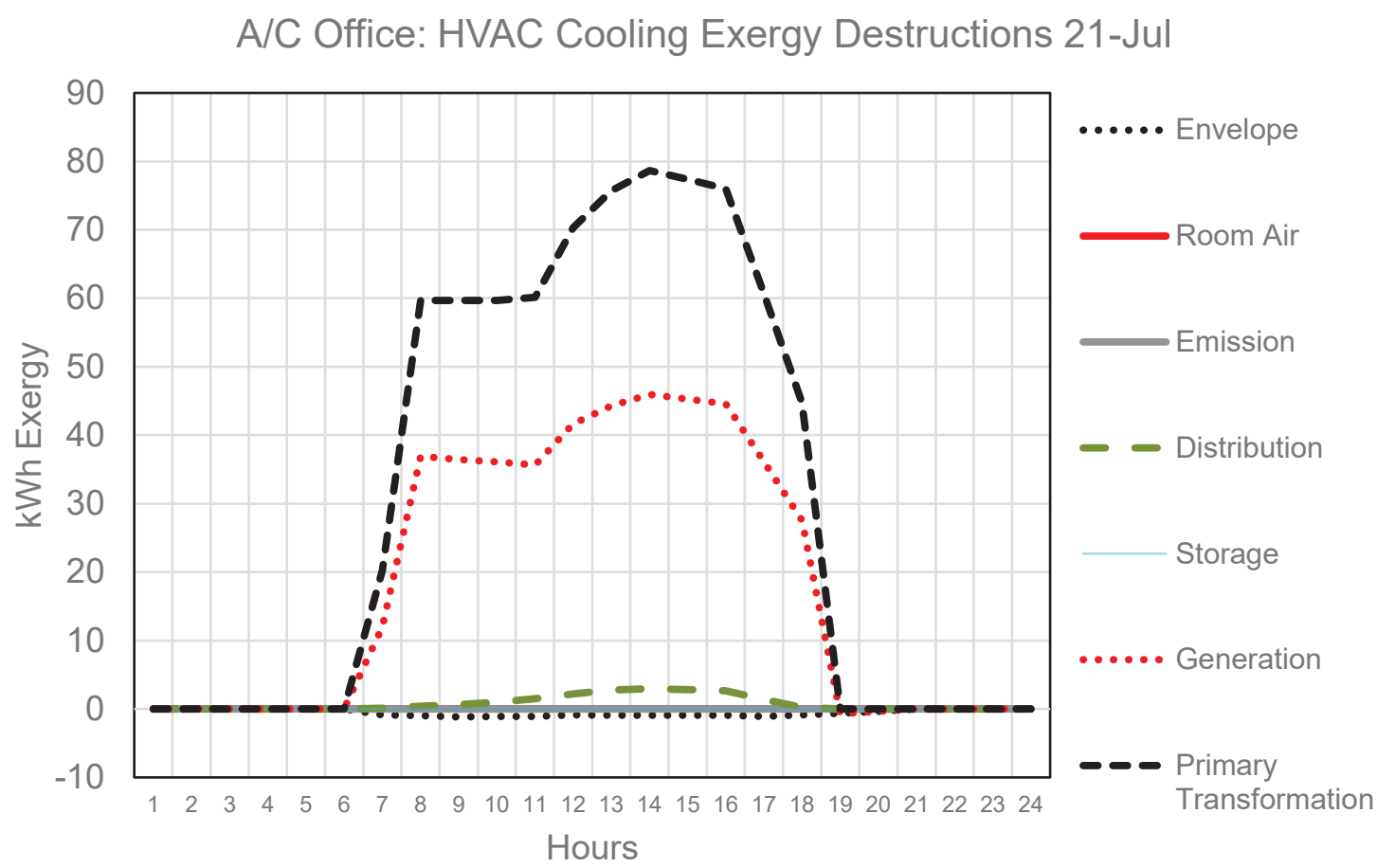

Fig. 11 A/C office: Summer Design Day. Baseline Exergy destructions by HVAC subsystems

In both archetypes, the largest exergy destructions occur at the primary transformation and the generation stage, representing $98 \%$ and $90 \%$ of the total exergy destructions for schools and offices respectively (Fig. 
12). This gives an initial insight on the thermodynamic performance of each component and provides a direct comparison of the magnitude of exergy irreversibilities of the two case studies.

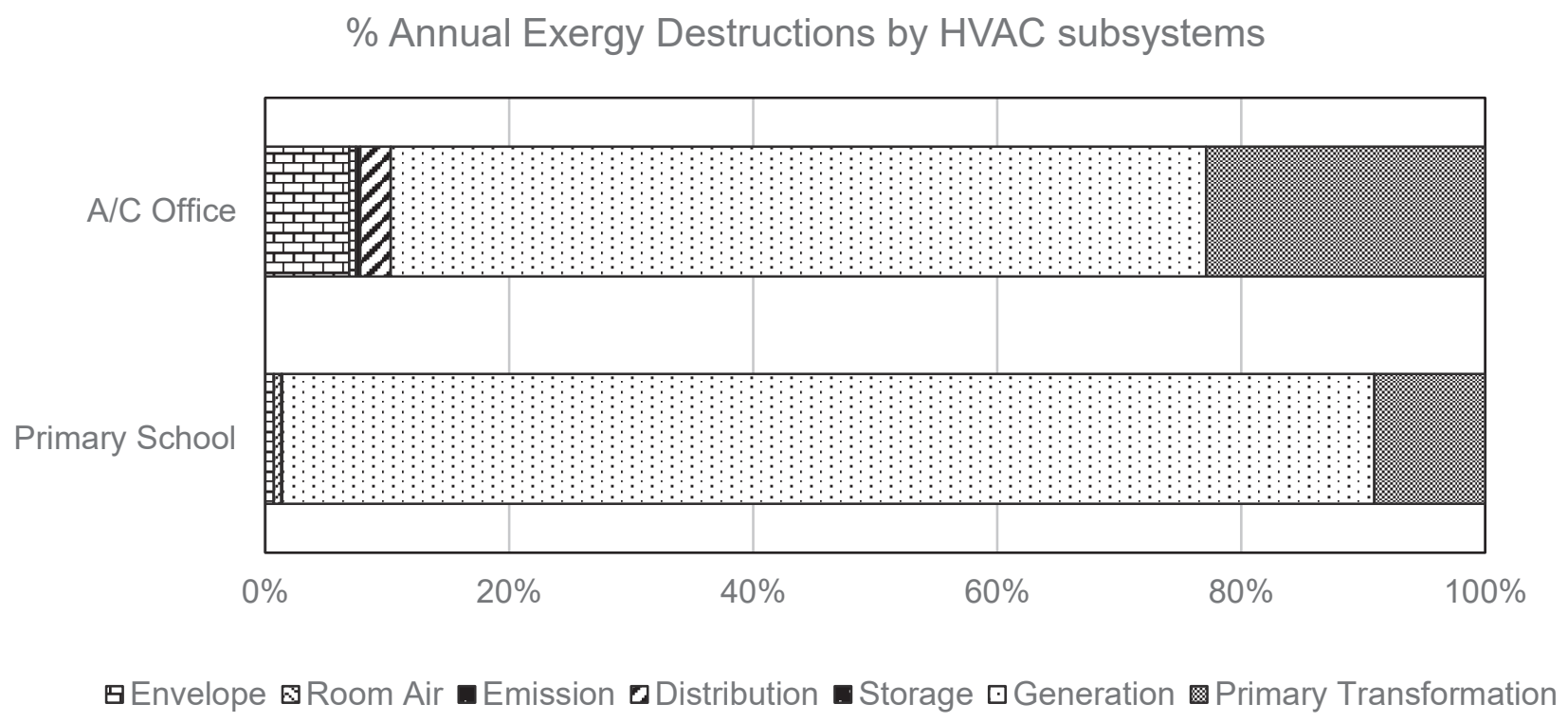

Fig. 12 Hourly exergy destructions and destruction percentage the HVAC subsystems of a typical primary school and an A/C office building

While a seemingly obvious solution would be to reduce this high irreversibilities, this should be preceded by the improvement of building generation systems. However, it is important to note that although some components may have higher exergy destructions rates than others, it is probable that these destructions are caused by exogenous origins (i.e. due to inefficiencies of other components within the system such as the envelope or emission subsystems). This means that passive measures may also be used for the minimisation of irreversibilities, but will have a lower impact on how the destructions are distributed between subsystems.

\subsection{Pre-optimisation parametric study}

To provide insight on the concept and test the EXRETOpt capabilities, a parametric analysis was performed for two subsystems: at the envelope subsystem by adding insulation, and at the generation subsystem by exploring different HVAC technologies.

\subsubsection{Impact of different insulation materials}

Firstly, in considering all the insulation options listed in Table 4, 64 simulations were performed for each archetype. For the school archetype, with $0.15 \mathrm{~m}$ of polyurethane envelope insulation, energy reductions up to $3.6 \%$ and an improvement of $6.8 \%$ (82 hours) in occupant comfort were achieved. For the office archetype, a 
maximum reduction of only $0.5 \%$ of energy savings and $0.9 \%$ of thermal comfort improvement was achieved through the use of $0.20 \mathrm{~m}$ of cork board insulation. The lower energy saving was due to an increasing demand on electricity to cover the higher summer cooling loads. The minimal comfort improvement was due to the occurrence of overheating during the summer months, so although an improvement was seen in heating season, summer months became more uncomfortable. Finally, exergy destructions in the primary school archetype were reduced by $2.7 \%$ (Fig. 13), while all insulation measures for the office resulted in an increase in total irreversibilities, ranging from a 1.0 to $2.5 \%$ increment (Fig. 14). In the primary school case, the reduction was higher due to a much lower input of fossil fuels, while in the office reductions were not achieved due to increased electricity consumption for cooling processes.
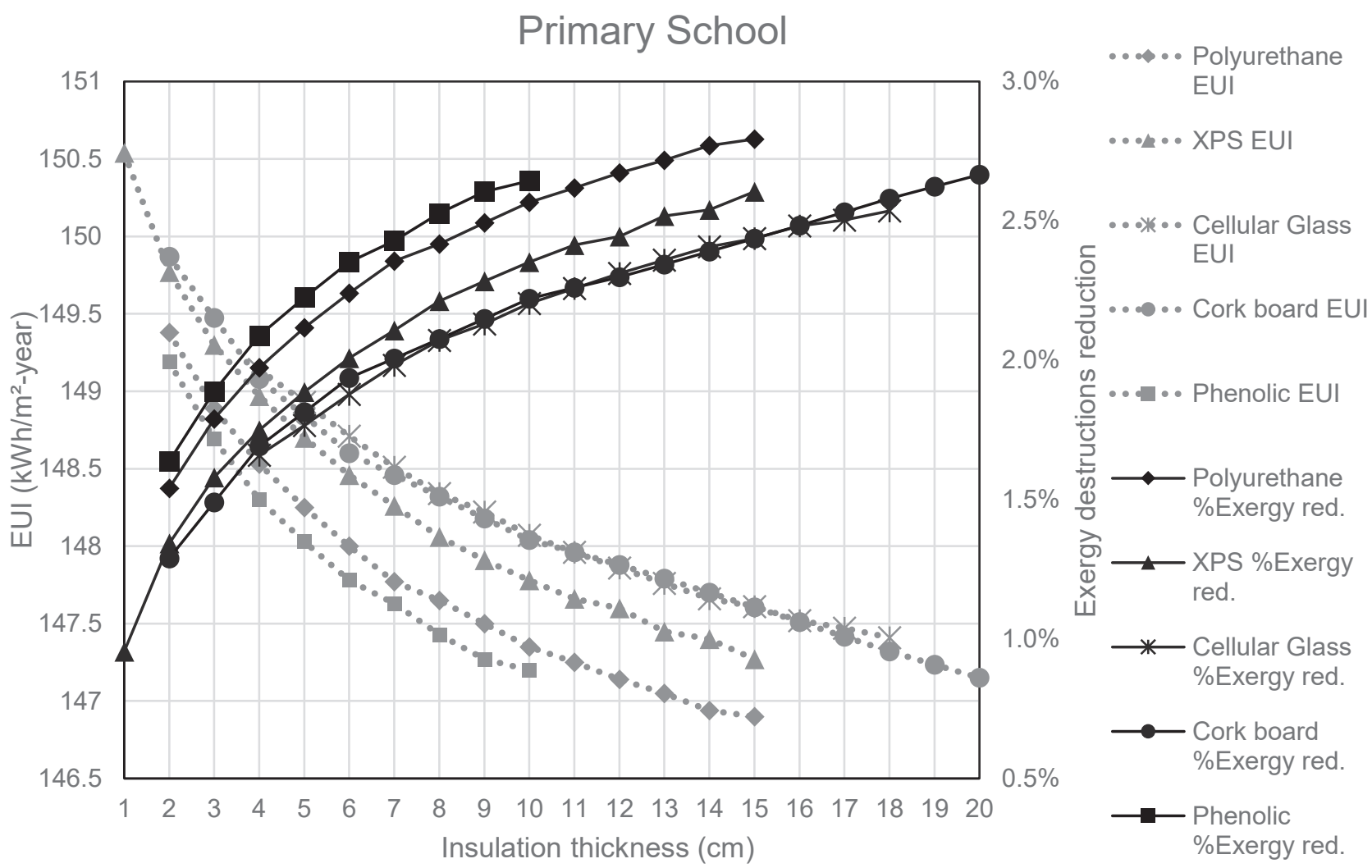

Fig. 13 Impact of different insulation types and thickness on energy use and exergy destructions: primary school case study. 


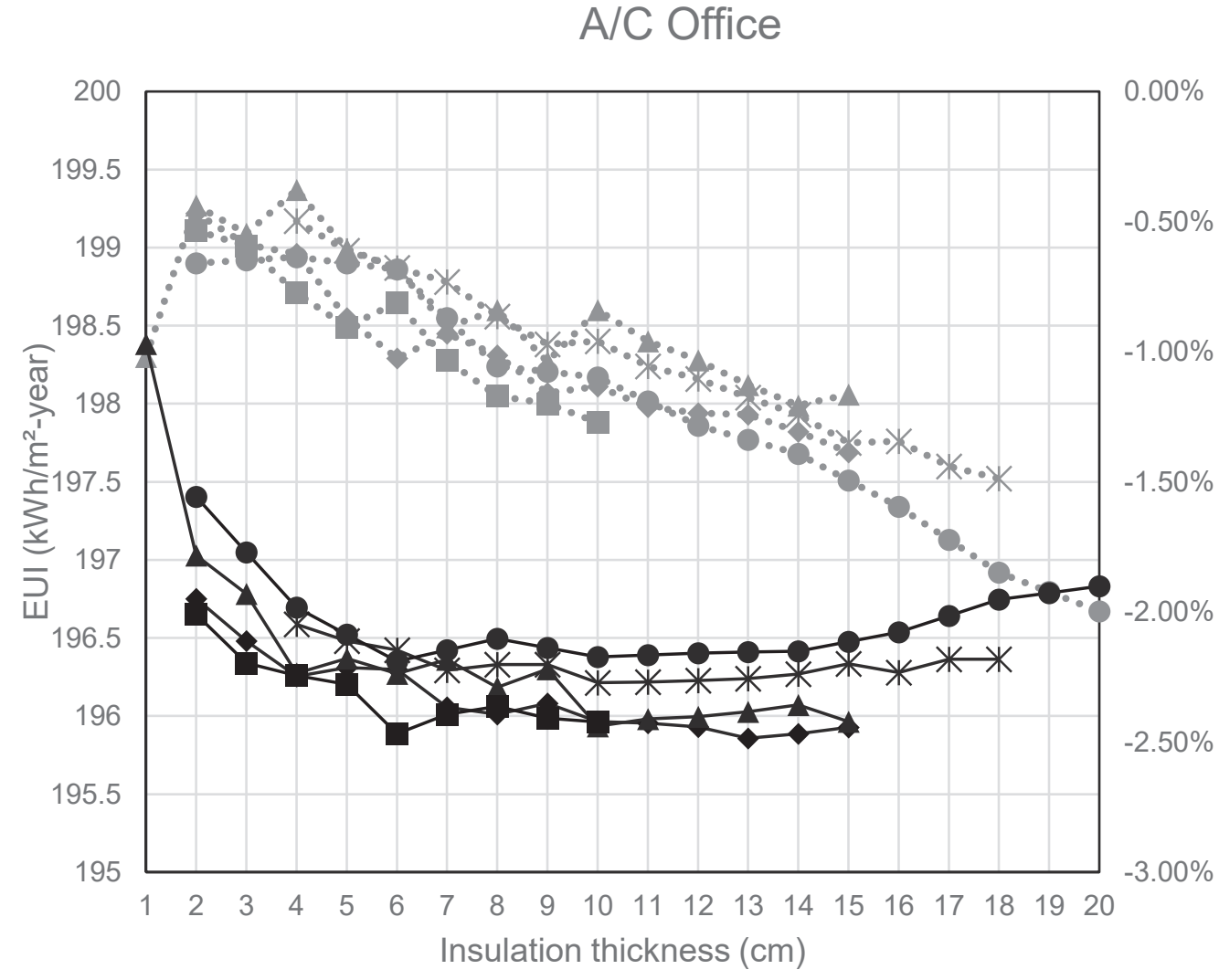

Fig. 14 Impact of different insulation types and thickness on energy use and exergy destructions: A/C Office case study.

\subsubsection{Impact of different HVAC systems}

To investigate the impact of different HVAC technologies, a further parametric analysis was performed by combining the insulation material with the best performance and nine different system configurations. From the insulation analysis, only the $0.06 \mathrm{~m}$ thickness was considered, since thicker values did not have a significant impact. For the school case, the use of $0.06 \mathrm{~m}$ of polyurethane insulation combined with a GSHP with low temperature underfloor heating $\left(35^{\circ} \mathrm{C}\right.$ supply $/ 25^{\circ} \mathrm{C}$ return) achieved a reduction of $56.7 \%$ in energy use, but with no major improvement in occupant thermal comfort. The highest exergy destruction minimization (21.1\%) was obtained through the use of District Heating with the same low-temperature emission system configuration (Fig. 15). This increased HVAC exergy efficiency from $0.7 \%$ to $14.7 \%$. 


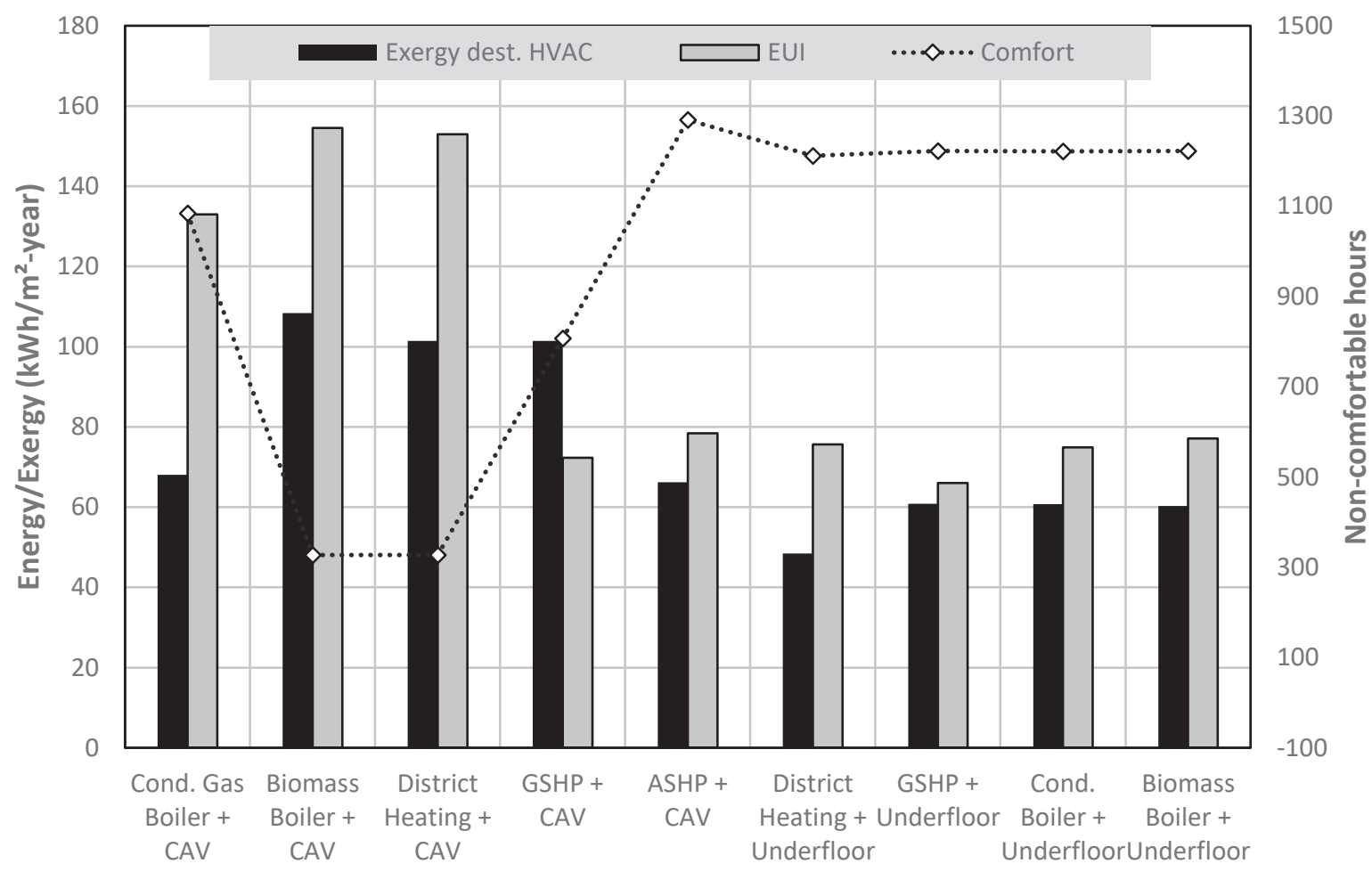

HVAC Configurations

Fig. 15 Influence of different HVAC configurations on energy, exergy destructions, and comfort levels: School case study with $0.06 \mathrm{~m}$ of polyurethane

For the office archetype, $0.06 \mathrm{~m}$ of cork board insulation combined with the GSHP with underfloor heating/cooling configuration achieved the maximum energy saving reduction (40.9\%) and the highest exergy destructions reduction (20.4\%). This system represents an increase in the exergy efficiency of the HVAC system from $6.9 \%$ to $23.1 \%$. Also, the system was able to reduce discomfort hours by $59.9 \%$ as compared to the baseline. The configuration that achieved better thermal comfort levels was the condensing gas and biomass boilers with underfloor heating. This achieved an improvement of $90.0 \%$, but with a lower decrease in exergy destructions (Fig. 16). 


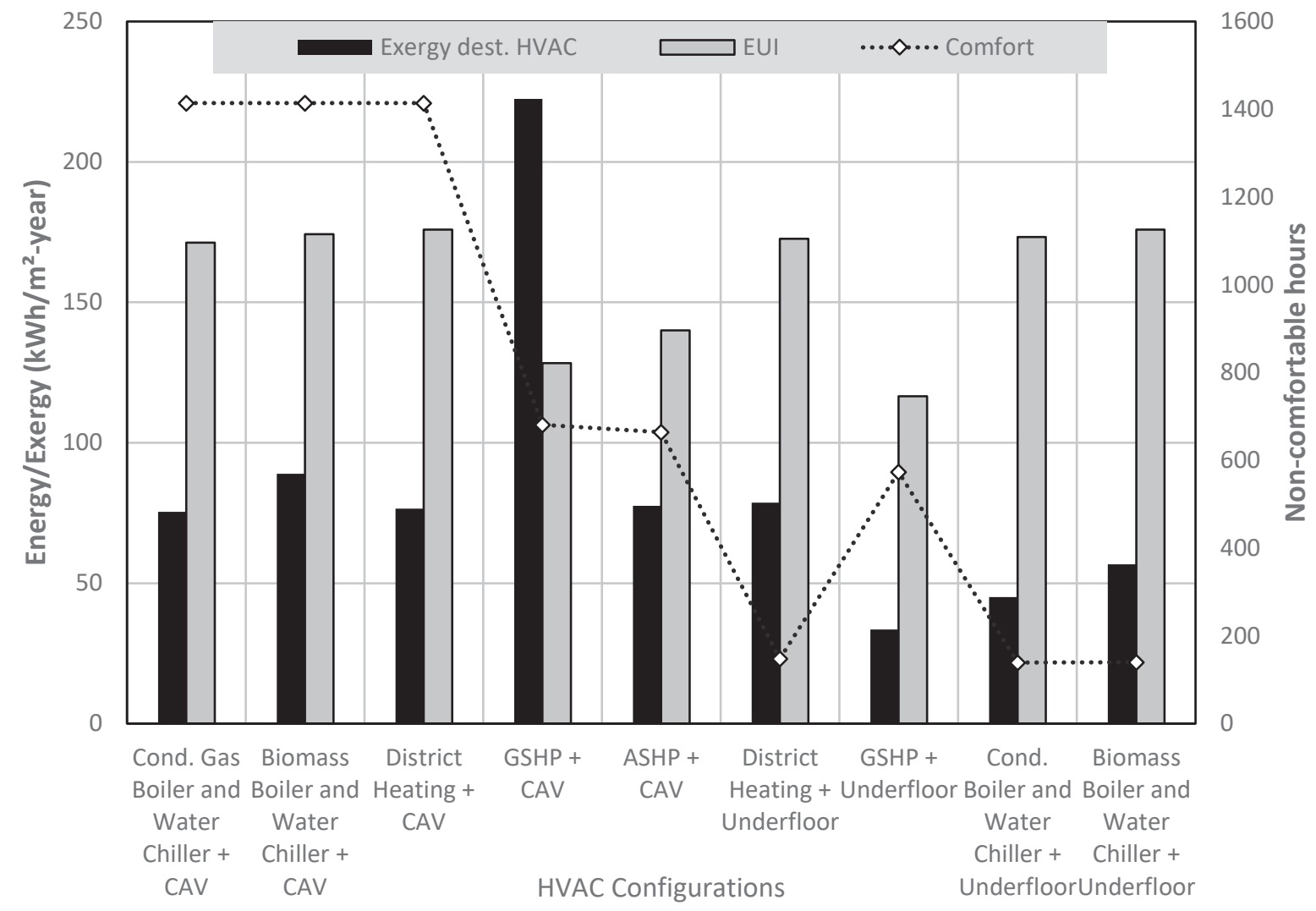

Fig. 16 Influence of different HVAC configurations on energy, exergy destructions, and comfort levels. Office case study with $0.06 \mathrm{~m}$ of cork board insulation.

\subsection{Retrofit Design Optimisation}

As the investigation of the impact of more technologies, configurations, and combinations between retrofit measures using the aforementioned approach is both impractical and time consuming, the multi-objective optimisation module was tested at this stage. As expected, the search space (all possible retrofit combinations) for the school and the office archetypes were $77,955,072,000$ and $389,775,360,000$ options, respectively. Since running both full parametric projects with a 4-core laptop would be unfeasible to due computational constraints, the use of an optimisation algorithm drastically reduced the number of simulations needed to at least achieve close to optimal results. It should be noted that an important task fundamental to this process is the identification of optimal computing settings to improve calculation time and accuracy. As GA needs a large population size to work efficiently [66] to define the Pareto front within the entire search space, the following settings were therefore defined for this study:

- $\quad$ Population size: 100

- Max Generations: 50

- Crossover Rate: $100 \%$

- $\quad$ Mutation Rate: $20 \%$ 
- Tournament Selection: 2

Following 170 hours of simulation, 5,015 and 5,013 simulations were gathered for the school and office, respectively. This represents less than $0.00001 \%$ of the entire search space. The "Pareto space" consisted of 344 possible solutions for the school, and 342 solutions for the office. Figures 17 and 18 show a comparison of all the simulated solutions and the non-dominated Pareto optimal solutions found by the model. Infiltration (ach) was taken as the colour range to illustrate the combined impact of this parameter on the three objectives. For both cases results show that the impact of an increasingly air-tight building in a temperate climate such as London (UK). It should be noted that as highlighted in the office case in particular, overheating risk in summer months is a factor that should be taken into consideration for further analysis. 


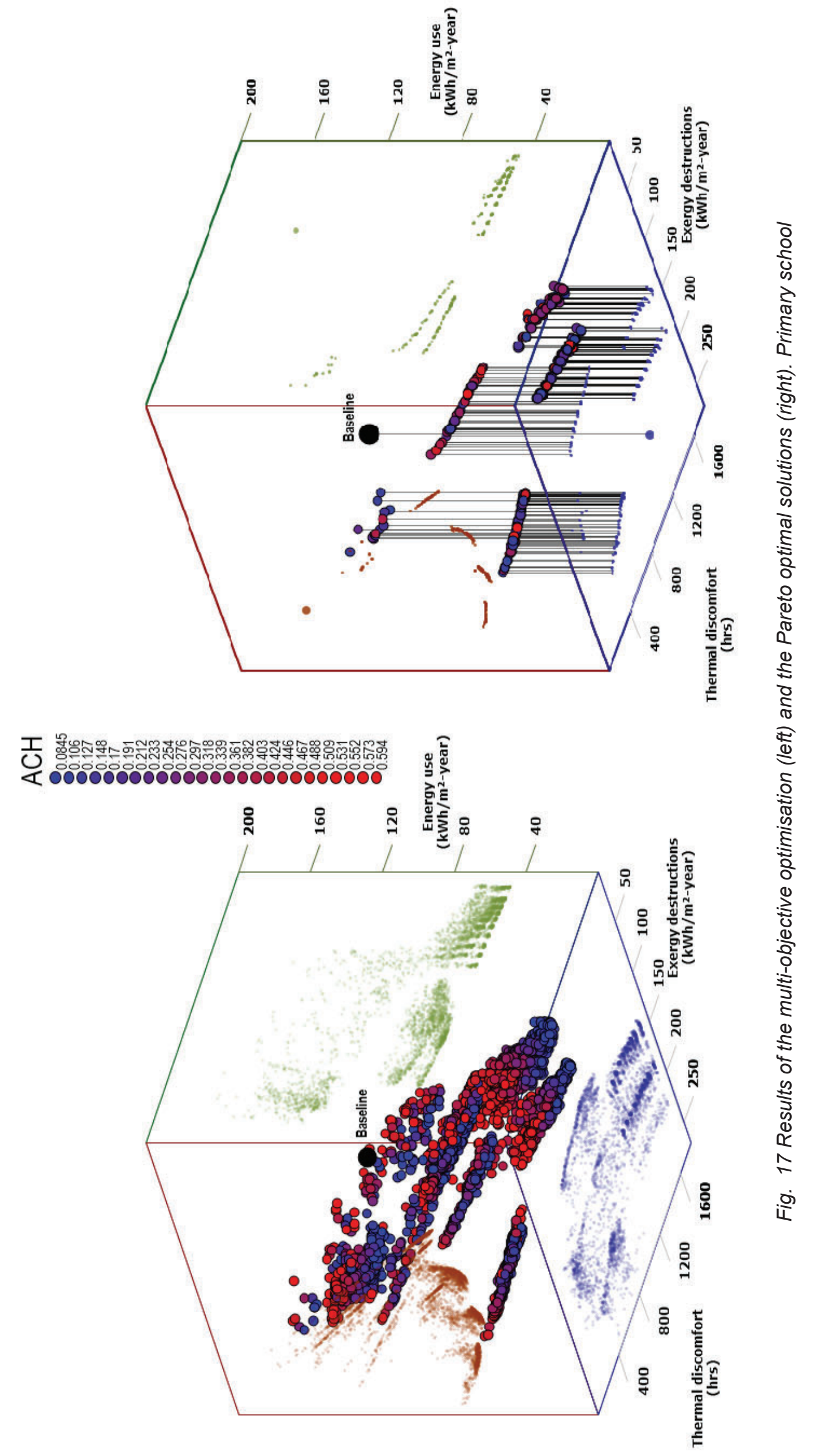




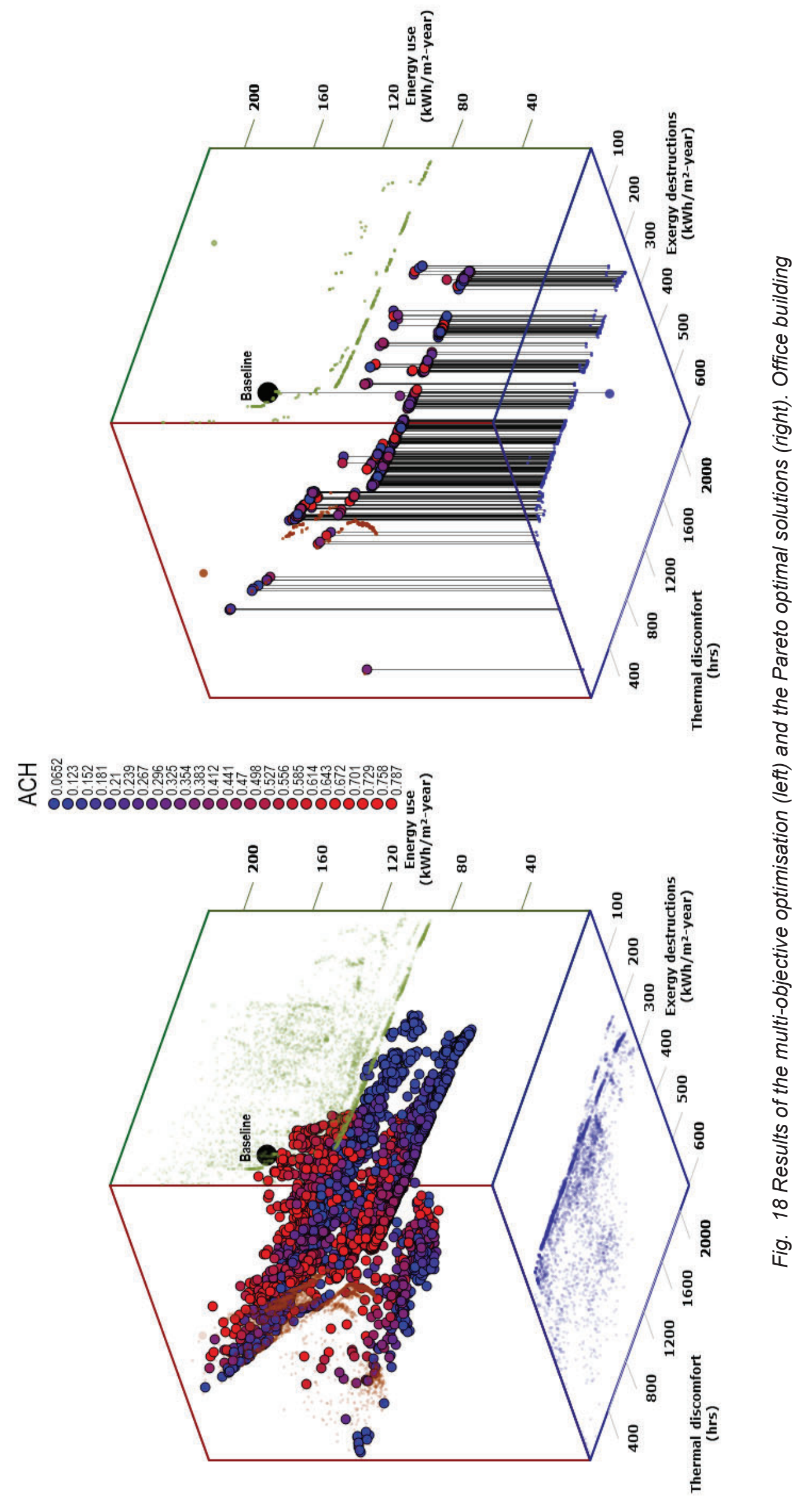


These "Pareto solutions" represent major improvements of the objectives with respect on the baseline, and the insulation and HVAC parametric studies. Since all the Pareto solutions can be considered 'equally good', the decision-maker can therefore make a choice depending on the importance given to each one of the objectives. Tables 6 (school) and 7 (office) illustrate the scenarios when objectives are optimised individually as well as the solution that is closer to the Utopia point $\left(\min Z_{1}(x), \min Z_{2}(x), \min Z_{3}(x)\right)$. The percentage reduction in each objective with respect to the baseline in highlighted inside parentheses.

The results show that measures such as triple glazed windows systems, high insulation thickness, low infiltration levels $(<0.2 \mathrm{ach})$, condensing boilers and GSHP systems dominate the best solutions. By individually optimizing either energy use or exergy destructions, some similarities can be noted in the obtained retrofit measures, thus indicating non-competitive objectives. Although by using exergy as an objective yields better comfort levels results. On the other hand, the competitive nature of thermal comfort with the other two objectives is noticeable in some parameters, especially for the HVAC characteristics (heating/cooling setpoint). Nevertheless, the model highlights that even the outputs of non-competitive objectives can lead to different outcomes. For example, in the school case if exergy destructions are used as the main objective, improvements of $62.1 \%$ in annual energy use, $57.9 \%$ of exergy destructions and $29.3 \%$ of thermal comfort can be achieved. However, by using energy use as the primary objective, it was possible to achieve improvements of $69.5 \%$ for energy use, $13.5 \%$ for exergy destructions, but this negatively impacts thermal comfort (-42.2\%). On the other hand, the office case shows that optimising either objective leads to an insignificant deterioration in the thermal comfort indicator. Yet, by individually optimising thermal comfort, reductions of $3.6 \%$ in energy use and $99.6 \%$ of discomfort were achieved, but with a deterioration in exergy destructions by $25.4 \%$.

In general, to achieve better solutions a compromise in objectives is required. The closest model to the utopia point considers the same weight to the three analysed objectives. For the primary school, this was achieved through a design based on a condensing gas boiler with a VAV emission system, with lower levels of insulation thickness, and an improvement of $30 \%$ (from 0.58 to 0.40 ) on the envelope's infiltration rate. The achieved reductions were $52.9 \%, 66.5 \%$, and $50.9 \%$ for the energy use, non-comfortable hours, and exergy destructions, respectively. The office improved by $50.3 \%, 79.8 \%$, and $33.0 \%$ for energy, thermal comfort, and irreversibilities, respectively, through the use of a GSHP with underfloor heating/cooling, with high insulation thickness for only the roof and the same infiltration rate as the baseline building ( $0.78 \mathrm{ach})$. 


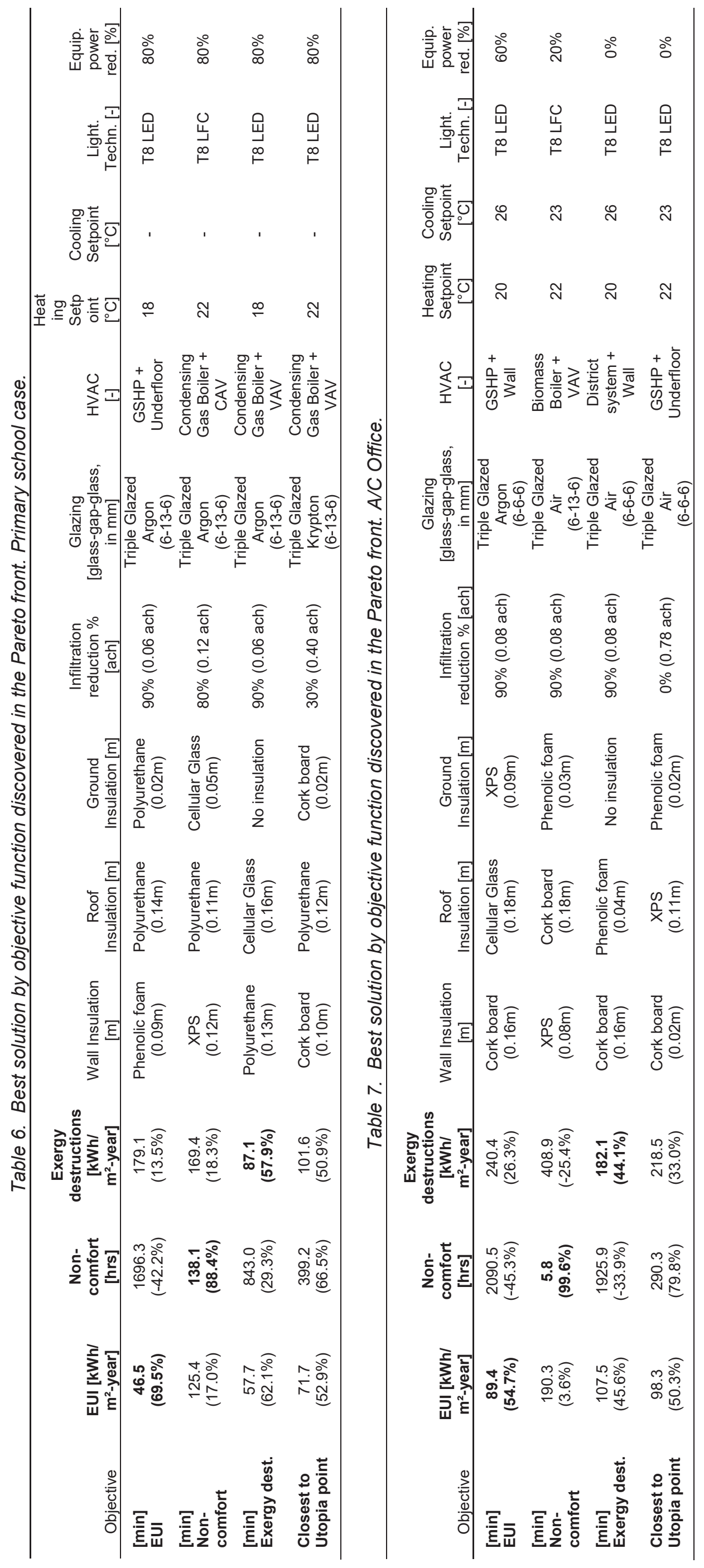




\section{Conclusions and Future work}

The focus of this paper was to propose a means by which exergy analysis can be integrated into a retrofitoriented energy simulation tool to strengthen the typical analysis applied to the comparison and selection of the most optimal building energy retrofit projects. Firstly, the tool (EXRETOpt) was tested though the application of a typical parametric process by exploring the impact of different types of insulation and HVAC configurations. This demonstrated that although this process leads to improvements in energy and exergy indicators, it is considered to be time-consuming.

By using the developed exergy-based multi-objective optimisation model, major improvements (close to optimal) were achieved in regards to the size of the search space. This method can provide more information than the typical optimisation methods based solely on energy analysis. The aim of implementing this model was to find the optimal retrofit measures by minimising energy use, exergy destructions, and thermal discomfort. As expected, optimal results based on energy analysis, and considering the London climate and without any economic constraints, are dominated by measures such as triple glazing, high exergy systems (condensing and biomass boilers), while having an airtight envelope. If we consider exergy as the main objective, solutions switch to systems such as district heating/cooling and GSHP while having envelopes with lower insulation levels and airtightness. Also, this approach leads to better thermal comfort conditions for the occupants, giving ERMs practitioners and decision makers more flexibility in the design process.

The model was able to identify a large space of Pareto solutions, where even the outputs of non-competitive objectives such as minimization of exergy destructions and energy use can lead to different results on the objectives. Significant output uncertainties exist due to the nature of building simulation tools, exergy analysis (e.g. reference environment) and the lack of empirical data. More model runs of the same projects are required to avoid results that can be obtained due to a hypothetical early convergence of the algorithm.

The most significant limitation of the study is that the cost objective function was not considered. This is an objective that would radically change the optimal solutions obtained in this research. As thermoeconomics is a valuable tool for optimisation of energy systems under second-law parameters, further work will aim to further the development of an exergoeconomic module by considering the exergy cost of streams, cost of retrofits 
(information on capital investment and operating cost of technologies), fuel tariffs and government incentives. In addition, it is recommended that a Life Cycle Analysis (LCA) of exergy destructions at the production stage of equipment and materials is considered. This is especially true for thermal insulations, which typically requires large amounts of exergy for manufacturing. The model application in real building will determine its robustness and limitations, and it is expected to apply the model in a real case in the near future.

\section{Acknowledgments}

The first author acknowledges support from The Mexican National Council for Science and Technology (CONACyT) through a scholarship to pursue doctoral studies with a CVU: 331698 and grant number: 217593.

\section{Nomenclature}

\begin{tabular}{|c|c|}
\hline COP & coefficient of performance (W/W) \\
\hline En $n_{\text {gen }}$ & energy demanded by the generation system, kWh \\
\hline$E U I$ & energy use index, kWh/m²-year \\
\hline$E x_{d e m}$ & exergy demand, kWh \\
\hline Ex $x_{\text {dest }}$ & exergy destructions, kWh \\
\hline$\dot{E} x_{\text {total,in }}$ & system average exergy input, kWh \\
\hline$F_{p}$ & primary energy factor (-) \\
\hline$F_{q}$ & quality factor (-) \\
\hline$P M V$ & predicted mean vote index \\
\hline$Q$ & energy demand, kWh \\
\hline$T_{0}$ & reference temperature, $\mathrm{K}$ \\
\hline$T_{i}$ & room temperature, $\mathrm{K}$ \\
\hline \multicolumn{2}{|c|}{ Greek symbols } \\
\hline$\eta_{g e n}$ & energy efficiency (-) \\
\hline$\psi_{\text {tot }}$ & exergy efficiency (-) \\
\hline \multicolumn{2}{|c|}{ Subscripts and superscripts } \\
\hline cook & cooking \\
\hline$d h w$ & domestic hot water \\
\hline elec & electricity \\
\hline hvac & heating, ventilation, and air conditioning \\
\hline ith & ith zone, equipment or energy source \\
\hline refr & refrigeration \\
\hline prim & primary energy \\
\hline$t_{k}$ & time step \\
\hline therm & thermal demand \\
\hline vent & ventilation \\
\hline
\end{tabular}

\section{References}

[1] DECC. The Future of Heating: Meeting the challenge. United Kingdom, 2013. 
[2] DECC. Energy Consumption in the UK. United Kingdom, 2014.

[3] Clarke JA, Johnstone CM, Kelly NJ, Strachan PA, Tuohy P. The role of built environment energy efficiency in a sustainable UK energy economy. Energy Policy. 2008;36(12):4605-9.

[4] Carbon Trust. Technology Innovation Needs Assessment (TINA). Non-Domestic Buildings. UK: Low Carbon Innovation Coordination Group; 2012.

[5] DCLG. L2B Conservation of fuel and power in existing buildings other than dwellings. United Kingdom, 2010.

[6] DCLG. Recast of the Energy Performance of Buildings Regulations. Department for Communities and Local Government. United Kingdom,2012.

[7] Siddharth V, Ramakrishna PV, Geetha T, Sivasubramaniam A. Automatic generation of energy conservation measures in buildings using genetic algorithms. Energy and Buildings. 2011;43(10):2718-26.

[8] Lee SH, Hong T, Piette MA, Taylor-Lange SC. Energy retrofit analysis toolkits for commercial buildings: A review. Energy. 2015;89:1087-100.

[9] LBNL, USDOE. DOE-2. James J. Hirsch \& Associates. USA, 2015.

[10] EnergyPlus, Energy Simulation Software, 2015 http://apps1.eere.energy.gov/buildings/energyplus/

[11] Chuah JW, Raghunathan A, Jha NK. ROBESim: A retrofit-oriented building energy simulator based on EnergyPlus. Energy and Buildings. 2013;66(0):88-103.

[12] Hong T, Piette MA, Chen Y, Lee SH, Taylor-Lange SC, Zhang R, et al. Commercial Building Energy Saver: An energy retrofit analysis toolkit. Applied Energy. 2015;159:298-309.

[13] Mauro GM, Hamdy M, Vanoli GP, Bianco N, Hensen JLM. A new methodology for investigating the costoptimality of energy retrofitting a building category. Energy and Buildings. 2015;107:456-78.

[14] Rysanek AM, Choudhary R. Optimum building energy retrofits under technical and economic uncertainty. Energy and Buildings. 2013;57(0):324-37.

[15] Klein SA. TRNSYS 17: A Transient System Simulation Program. Solar Energy Laboratory UoW, Madison, USA, 2010.

[16] The_MathWorks I. MATLAB and Statistics Toolbox Release 2012b. Natick, Massachusetts, USA, 2012.

[17] Asadi E, Silva MGd, Antunes CH, Dias L, Glicksman L. Multi-objective optimization for building retrofit: A model using genetic algorithm and artificial neural network and an application. Energy and Buildings. 2014;81(0):444-56.

[18] Diakaki C, Grigoroudis E, Kolokotsa D. Towards a multi-objective optimization approach for improving energy efficiency in buildings. Energy and Buildings. 2008;40(9):1747-54.

[19] Attia S, Hamdy M, O'Brien W, Carlucci S. Assessing gaps and needs for integrating building performance optimization tools in net zero energy buildings design. Energy and Buildings. 2013;60(0):110-24.

[20] Nguyen A-T, Reiter S, Rigo P. A review on simulation-based optimization methods applied to building performance analysis. Applied Energy. 2014;113(0):1043-58.

[21] Evins R. A review of computational optimisation methods applied to sustainable building design. Renewable and Sustainable Energy Reviews. 2013;22(0):230-45.

[22] Asadi E, da Silva MG, Antunes CH, Dias L. Multi-objective optimization for building retrofit strategies: A model and an application. Energy and Buildings. 2012;44(0):81-7.

[23] Malatji EM, Zhang J, Xia X. A multiple objective optimisation model for building energy efficiency investment decision. Energy and Buildings. 2013;61(0):81-7. 
[24] Hammond GP, Stapleton AJ. Exergy analysis of the United Kingdom energy system. Proceedings of the Institution of Mechanical Engineers, Part A: Journal of Power and Energy. 2001;215(2):141-62.

[25] Shukuya M. Exergy concept and its application to the built environment. Building and Environment. 2009;44(7):1545-50.

[26] Dincer I. The role of exergy in energy policy making. Energy Policy. 2002;30(2):137-49.

[27] Gasparatos A, El-Haram M, Horner M. Assessing the sustainability of the UK society using thermodynamic concepts: Part 2. Renewable and Sustainable Energy Reviews. 2009;13(5):956-70.

[28] ECB-Annex 37. Technical Synthesis Report: Low Exergy Systems for Heating and Cooling of Buildings, IEA ECBCS. UK, 2007.

[29] ECB-Annex 49. Detailed Exergy Assessment Guidebook for the Built Environment, IEA ECBCS. Fraunhofer IBP, 2011.

[30] Jansen SC, Terés-Zubiaga J, Luscuere PG. The exergy approach for evaluating and developing an energy system for a social dwelling. Energy and Buildings. 2012;55(0):693-703.

[31] Terés-Zubiaga J, Jansen SC, Luscuere P, Sala JM. Dynamic exergy analysis of energy systems for a social dwelling and exergy based system improvement. Energy and Buildings. 2013;64(0):359-71.

[32] Favrat $D$, Marechal $F$, Epelly $O$. The challenge of introducing an exergy indicator in a local law on energy. Energy. 2008;33(2):130-6.

[33] Sakulpipatsin, P., Boelman, E. and Schmidt, D. Exergy analysis applied to building design. 7th Nordic Symposium on Building Physics. Reykjavik, Iceland, Jun. 13-15, 2005.

[34] Schlueter A, Thesseling F. Building information model based energy/exergy performance assessment in early design stages. Automation in Construction. 2009;18(2):153-63.

[35] Valdés M, Durán MD, Rovira A. Thermoeconomic optimization of combined cycle gas turbine power plants using genetic algorithms. Applied Thermal Engineering. 2003;23(17):2169-82.

[36] Mofid G-B, Hamed G. Exergoeconomic optimization of gas turbine power plants operating parameters using genetic algorithms: A case study. Thermal Science 2011;15(1):43-54.

[37] Ahmadi P, Dincer I, Rosen MA. Exergy, exergoeconomic and environmental analyses and evolutionary algorithm based multi-objective optimization of combined cycle power plants. Energy. 2011;36(10):5886-98.

[38] Kaviri AG, Jaafar MNM, Lazim TM. Modeling and multi-objective exergy based optimization of a combined cycle power plant using a genetic algorithm. Energy Conversion and Management. 2012;58(0):94-103.

[39] Chen QL, Yin QH, Hua B. An exergoeconomic approach for retrofit of fractionating systems. Energy. 2002;27(1):65-75.

[40] Baghernejad A, Yaghoubi M. Exergoeconomic analysis and optimization of an Integrated Solar Combined Cycle System (ISCCS) using genetic algorithm. Energy Conversion and Management. 2011;52(5):2193-203.

[41] Schmidt D. Methodology for the Modelling of Thermally Activated Building Components in Low Exergy Design. Doctoral Thesis, Kungliga Tekniska Högskolan - The Royal Institute of Technology Department of Civil and Architectural Engineering, 2004.

[42] Rosen M, Bulucea CA. Using Exergy to Understand and Improve the Efficiency of Electrical Power Technologies. Entropy. 2009;11(4):820-35.

[43] Pout CH. Proposed Carbon Emission Factors and Primary Energy Factors for SAP 2012. BRE, Technical papers supporting SAP 2012. UK, 2011.

[44] Angelotti A, Caputo P, Solani G. Dynamic exergy analysis of an air source heat pump. 1st International Exergy, Life Cycle Assessment, and Sustainability Workshop \& Symposium (ELCAS). 2009:8. 
[45] Zhang Y, Korolija I. Performing complex parametric simulations with jEPlus. SET2010 - 9th International Conference on Sustainable Energy Technologies. Shanghai, China, 2010.

[46] Miller C, Hersberger C, Jones M. Automation of common building energy simulation workflows using python In: IBPSA editor. Conference Automation of common building energy simulation workflows using python, Chambery, France. p. 210-7.

[47] ARUP. Low Carbon Routemap for the UK Built Environment. In: Board TGC, editor. UK, 2013.

[48] AECOM. Spon's Architects' and Builders' Price Book. 140th Taylor \& Francis Group, 2015.

[49] Just Insulation. URL: http://www.just-insulation.com/002-brands, Accessed: 10-Oct-2015.

[50] Zhang Y. Use jEPlus as an efficient building optimisation tool. CIBSE ASHRAE Technical Symposium. Imperial College, London UK, 2012.

[51] Spencer H. The principles of biology, by Herbert Spencer. New York: D. Appleton and company, 1898.

[52] ASHRAE. ANSI/ASHRAE Standard 55-2004. Thermal Environmental Conditions for Human Occupancy. American Society of Heating, Refrigerating and Air-conditioning Engineers; USA, 2004.

[53] Pout CH, Mackenzie F, Bettle R. Carbon Emissions from Non-Domestic Buildings: 2000 and beyond. . Report 442 for Department of Environment, Food and Rural Affairs (DEFRA). Building Research Establishment Ltd (BRE). UK, 2002

[54] Bruhns HR, Steadman P, Herring H, Moss S, Rickaby PA. Types, numbers, and floor areas of nondomestic premises in England and Wales, classified by activity. Environment and Planning B: Planning and Design. 2000;27(5):641-65.

[55] Korolija I, Marjanovic-Halburd L, Zhang Y, Hanby VI. UK office buildings archetypal model as methodological approach in development of regression models for predicting building energy consumption from heating and cooling demands. Energy and Buildings. 2013;60(0):152-62.

[56] Steadman P, Bruhns H, Gakovic B. Inferences about built form, construction, and fabric in the nondomestic building stock of England and Wales. Environment and Planning B: Planning and Design. 2000;27:733-58.

[57] EFA. Baseline designs for schools: guidance. UK: Education Funding Agency; 2014.

[58] DEWO. The Building Regulations 1985 - Approved Document L: Conservation of Fuel and Power (1985 edition). London, UK, 1985.

[59] CIBSE. Guide A. Environment design. London, UK2015.

[60] Daly D, Cooper P, Ma Z. Understanding the risks and uncertainties introduced by common assumptions in energy simulations for Australian commercial buildings. Energy and Buildings. 2014;75(0):382-93.

[61] SIMLAB. V2.2, Simulation environment for uncertainty and sensitivity analysis. Developed by the Joint Research Center of the European Commission. 2011.

[62] Tian W. A review of sensitivity analysis methods in building energy analysis. Renewable and Sustainable Energy Reviews. 2013;20(0):411-9.

[63] Godoy-Shimizu D, Armitage P, Steemers K, Chenvidyakarn T. Using Display Energy Certificates to quantify schools' energy consumption. Building Research \& Information. 2011;39(6):535-52.

[64] Armitage P, Godoy-Shimizu D, Steemers K, Chenvidyakarn T. Using Display Energy Certificates to quantify public sector office energy consumption. Building Research \& Information. 2015;43(6):691-709.

[65] Hong S, Steadman P. An analysis of Dispaly Energy Certificates for Public Buildings, 2008 to 2012. In: CIBSE, editor.: UCL Energy Institute; 2013. 
[66] Roeva O, Fidanova S, Paprzycki M. Influence of the population size on the genetic algorithm performance in case of cultivation process modelling. 2013 Federated Conference on Computer Science and Information Systems (FedCSIS), Krakow, Poland, 2013, p. 371-6. 